\title{
Zum Klagsziel der actio pigneraticia in personam contraria in D. 13,7,9pr.
}

\author{
Philipp Scheibelreiter \\ Professor für Antike Rechtsgeschichte und Römisches Recht, Universität \\ Wien, Institut für Römisches Recht und Antike Rechtsgeschichte, \\ Schenkenstraße 8-10, A-1010 Wien \\ philipp.scheibelreiter@univie.ac.at
}

\section{Summary}

In D. 13,7,9pr. (Ulp. 28 ad ed.) a debtor, who has handed over a res aliena as pledge to a creditor, will be sued with the iudicium contrarium. Whereas most handbooks of Roman law understand the aim of the actio pigneraticia contraria as the debtor's duty to replace the res aliena by a new pledge, owned by the debtor, the sources do not necessarily lead to this conclusion. From the procedural perspective and the condemnatio pecuniaria of classical Roman law (instead of specific performance) this solution seems to be problematic and may have been developed under in any case influence of Justinianic law. Also on the basis of the concept of pignus as obligatio re contracta, it is submitted that the debtor's obligation could only have concerned the alien thing itself; beside this, the aim of the actio contraria was compensation for the creditor's damages.

\section{Keywords}

Actio pigneraticia contraria - pignus - specific performance - bonae fidei iudicia

Gegenstand der vorliegenden Untersuchung ist nur die erste von zwei Sachverhaltsvarianten eines Satzes, der von den Kompilatoren als principium eines längeren Abschnitts aus dem 28. Buch des ulpianischen Ediktkommentars angeordnet worden ist. Das gesamte Fragment D. 13,7,9pr. (Ulp. 28 ad ed.) lautet: 
Si rem alienam mihi debitor pignori dedit aut malitiose in pignore versatus sit, dicendum est locum habere contrarium iudicium.

Wenn mir der Schuldner eine fremde Sache zum Pfand übergab oder sich arglistig hinsichtlich der Pfandsache verhielt, dann ist zu sagen, dass die Konträrklage am Platz sei.

Der Ego erhält von seinem Schuldner eine Sache zum Pfand übergeben, die fremd ist, also nicht dem Schuldner gehört. Pignori dare bezeichnet hier nicht wie so oft bloß die Bestellung zum Pfand ${ }^{1}$, sondern ist wörtlich auf die körperliche Übergabe, die datio der Sache zu beziehen. Insofern unterscheidet sich das rem alienam pignori dare in D. 13,7,9pr. etwa von der gleichen Formulierung des Paulus in D. 13,7,41 (Paul. 3 quaest.): 'Rem alienam pignori dedisti, deinde dominus rei eius esse coepisti: datur utilis actio pigneraticia creditori'. Hier kann aus der nachträglich vom Juristen zugestandenen actio pigneraticia (in rem) utilis ${ }^{2}$ an den Gläubiger erschlossen werden, dass die Sache eben nicht übergeben worden war und pignori dare den Versuch des Schuldners Tu beschreibt, eine ihm fremde Sache als Sicherheit zu bestellen ${ }^{3}$.

In D. 13,7,9pr. hingegen indiziert die Erteilung der actio pigneraticia in personam contraria, dass der debitor dem creditor Ego eine res aliena übergeben hat ${ }^{4}$.

Kombiniert wird dieser erste Sachverhalt des Pfandrealvertrags über eine res aliena mit einem zweiten, nämlich der dolosen Beeinträchtigung der Pfandsache durch den Schuldner, dem malitiose versari in pignore. Was bedeutet dies konkret? ${ }^{5}$

$1 \quad$ D. Schanbacher, Die Konvaleszenz von Pfandrechten im klassischen römischen Recht, Berlin 1987, S. 113 Anm. 582 mit weiteren Belegen. Allgemein zu pignori dare und besitzlosem Pfand vgl. dazu M. Kaser, Studien zum römischen Pfandrecht, II:Actio pigneraticia und actio fiduciae, Tijschrift voor Rechtsgeschiedenis, 47 (1979), S. 200 mit Anm. 27.

2 Vgl. nur Schanbacher, Konvaleszenz (supra, n. 1), S. 113 Anm. 585: 'Gewiss nicht gemeint ist hier die (persönliche) actio pigneraticia contraria, arg. utilis'. Zur Frage, worauf sich die Analogie bezog, nämlich: auf eine Fiktion des 'in bonis esse' oder eine Verurteilung aufgrund eines späteren Erwerbs der Sache durch den Pfandbesteller oder seiner Eigentümerstellung zum Zeitpunkt der litis contestatio vgl. J.D. Harke, Actio utilis, Anspruchsanalogie im römischen Recht, Berlin 2016, S. 268.

3 Dies erklärt sich zum einen aus der Tatsache, dass die actio utilis sich nicht auf die actio in personam beziehen kann, zum anderen daraus, dass das Klagsziel der dinglichen Klage eben die Erlangung der Sache ist, welche sich also nicht beim Gläubiger befinden und somit bei Pfandbestellung(sversuch) auch nicht übergeben worden sein kann.

4 Zur Abgrenzung von D. 13,7,41 zu D. 13,7,9pr. vgl. Schanbacher, Konvaleszenz (supra, n. 1), S. 113 Anm. 585, der auch auf D. 13,7,16,1 (Paul. 29 ad ed.); D. 13,7,36,1 (Ulp. 11 ad ed.) und D. 13,7,32 (Marc. 4 reg.) verweist.

5 Die Wendung könnte in Zusammenhang mit dolosem Verhalten des Verwahrers belegt sein, glaubt man G. Rotondi, Scritti giuridici, vol. II /1, Milano 1922, S. 19, der - allerdings ohne eine 
Die Übersetzungen sprechen davon, dass: der Schuldner 'böswillig in Bezug auf das Pfand verfahren sein sollte', 'hinsichtlich der Pfandsache arglistig handelt $^{77}$, 'contrives something malicious to it's, 'si è comportato dolosamente riguardo al pegno'9 oder 'ten aanzien van het pand arglistig gehandeld heeft'10. Gaius bringt, in anderem Kontext, ein Beispiel für das malitiose facere, wenn er davon spricht, dass ein vermachter Sklave Abrechnungen übermalt habe (rationes interlinere $)^{11}$. Ulpian belässt es bei der generellen Beschreibung des Pfandschuldner-Verhaltens als malitiose versari ${ }^{213}$. Allerdings ist der Zusatz auch wegen des Wechsels vom Indikativ Perfekt: dedit (Sachverhalt 1) zu Konjunktiv Perfekt versatus sit (Sachverhalt 2$)^{14}$ als Glossem verdächtigt worden ${ }^{15}$.

konkrete Quelle dazu anzugeben - vom malitiose in re deposita versari spricht, welches auch in spätklassischen Quellen auf die Deliktsnatur des Verwahrungsvertrages schließen lasse.

6 Das Corpus Iuris Civilis Romani, ins Deutsche übersetzt, Band 2: Pandekten Buch 12-27, hrsg. von K.E. Otto, B. Schilling, K.F.F. Sintenis, Leipzig 1831, S. 120.

7 Übersetung R. Zimmermann, in: Corpus Iuris Civilis, Text und Übersetzung, II: Digesten 11-20, hrsg. von O. Behrends, R. Knütel, B. Kupisch, H.H. Seiler, Heidelberg 1999, S. 180; zur Übersetzung von malitiose versari mit 'arglistig handeln' vgl. ferner Handlexikon zu den Quellen des römischen Rechts, hrsg. von H. Heumann, E. Seckel, Jena " 1907 [ND Graz 1971], S. 333 s.v. malitia, und S. 605 s.v. versare (4).

8 P. Birks, in: The Digest of Justinian, Volume I, hrsg. von A. Watson, Philadelphia 1998, S. 480.

9 Iustiniani Augusti digesta seu pandecta, Testo e traduzione, III 12-19, hrsg. von S. Schipani, Milano 2007, S. 114.

10 E. Slob / M. Van de Vrugt, in: Corpus Iuris Civilis, Tekst en Vertaling, III: Digesten 11-24, hrsg. von J.E. Spruit, R. Feenstra, K.E.M. Bongenaar, Zutphen 1996, S. 173.

11 D. 30,67pr. (Gai. 1 de legatis ad ed. praet.) ‘Servus uni ex heredibus legatus si quid in hereditate malitiose fecisse dicetur (forte rationes interlevisse), non aliter adiudicandus est, quam ex eo volentibus coheredibus quaestio habeatur. Idem est si extraneo fuit legatus - Wenn ein einem von den Miterben vermachter Sklave hinsichtlich der Erbschaft arglistig gehandelt haben soll (etwa, indem er Abrechnungen übermalt hat), so ist er nicht anders zuzusprechen, als wenn gegen ihn auf Verlangen der Miterben eine Befragung stattgefunden hat. Dasselbe gilt, wenn er einem Außenstehenden vermacht worden ist'.

12 P. Stein, Fault in the formation of contract in Roman law and Scots law, Aberdeen 1958, S. 110, denkt hier an tatsächlich belegte Anwendungsfälle 'giving as pledge something which is already pledged to another, or a res aliena, or aes pro auro; vgl. dazu unten unter 3 .

13 Das weckt unwillkürlich Assoziationen zum dolo malo factum esse in der intentio der actio de dolo, vgl. zu deren Klageformel vgl. O. Lenel, Das Edictum perpetuum, Ein Versuch seiner Wiederherstellung, Leipzig 31927, S. 114-116. G. Provera, Contributi a una teoria di iudicia contraria, Turin 1951, S. 97-98 und A. d'Ors, Observaciones sobre el 'edictum de rebus creditis', Studia et Documenta Historiae et Iuris, 19 (1953), S. 134-201, 19o sehen in der expliziten Erwähnung des dolosen Verhaltens in der zweiten Sachverhaltsvariante einen Hinweis auf auch die in Variante 1 geforderte dolose Begehung, die sich aus der hier ursprünglich kompetenten actio de dolo erkläre.

14 Stein, Fault (supra, n. 12), S. 131.

15 Die Passage aut - versatus sit wurde als Glossem verdächtigt, da sie suggeriert, dass die Verpfändung der fremden Sache wissentlich erfolgt sei, vgl. F. Schwarz, Die Konträrklagen, zSs romAbt, 71 (1954), S. 111-220, 142-143; Stein, Fault (supra, n. 12), S. 132. H. Kreller, Formula 
Für beide Verhaltensweisen, also das rem alienam pignori dare und das malitiose in pignore versari stehe nach Ulpian dem Gläubiger gegen den Schuldner die Anwendung des contrarium iudicium offen: die actio pigneraticia in personam contraria ${ }^{16}$. Worauf war diese aber gerichtet? Ehe dieser Frage nachgegangen werden kann, ist kurz der Kontext des Fragmentes zu beleuchten.

Die Textüberlieferung ist unproblematisch ${ }^{17}$. Im 28 . Buch des Ediktskommentars behandelt Ulpian die persönliche Pfandrechtsklage ${ }^{18}$. Diese actio pigneraticia in factum concepta, die in der Rubrik de rebus creditis verortet war ${ }^{19}$, lautet in der Rekonstruktion von Lenel ${ }^{20}$ :

Gaius Aquilius iudex esto. Si paret Aulum Agerium Numerio Negidio rem, qua de agitur, ob pecuniam debitam pignori dedisse eamque pecuniam solutam eove nomine satisfactum esse aut per Numerium Negidium stetisse, quo minus solveretur, eamque rem Aulo Agerio redditam non esse, quanti ea res erit, tantam pecu-
Gaius Aquilius soll Richter sein. Wenn es sich erweist, dass Aulus Agerius dem Numerius Negidius die Sache, um die prozessiert wird, wegen einer Geldschuld zum Pfand gegeben hat, und diese Geldschuld bezahlt worden oder aus diesem Titel bereits befriedigt worden ist oder es an $\mathrm{Nu}-$ merius Negidius lag, dass nicht geleistet wird, und diese Sache dem Aulus Agerius noch nicht zurückgegeben wor-

fiduciae und Pfandedikt, zss romAbt 62 (1942), S. 143-208, S. 156 Anm. 49 vermutet eine Interpolation, da der zweite Sachverhalt mit dem hier kommentierten Pfandgegenstand nichts zu tun habe.

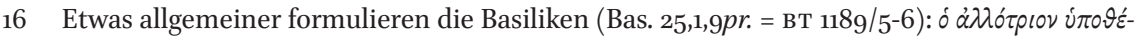

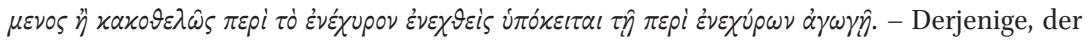
eine fremde Sache verpfändet oder sich böswillig hinsichtlich der Pfandsache verhält, unterliegt der Klage wegen der Pfänder'.

17 Einzige Auffälligkeit ist, dass in den Handschriften des Codex Parisinus Pa und Vaticanus jeweils das est zwischen dicendum und locum fehlt.

18 O. Lenel, Palingenesia Iuris Civilis, II, Leipzig 1889, S. 583-585.

19 Das Edikt ist nicht erhalten; Lenel, Edictum perpetuum (supra, n. 13), S. 232 verweist aber auf D. 12,1,1,1 (Ulp 26 ad ed.), wo es allgemein heißt: praetor ... de pignore edixit; vgl. Kaser, Pfandrecht, II (supra, n. 1), S. 197. Kaser rekonstruiert als ein Pfandedikt: 'Quod ob pecuniam debitam pignori datum esse dicetur, de eo iudicium dabo' (199); zustimmend etwa M. Brauckmann, Pignus, Das Pfandrecht unter dem Einfluß der vorklassischen und klassischen Tradition der römischen Rechtswissenschaft, Göttingen 2008, S. 46.

20 Zitiert aus Lenel, Edictum perpetuum (supra, n. 13), S. 255; ebenso Kaser, Pfandrecht, II (supra, n. 1), S. 5; D. Mantovani, Le formule del processo privato Romano, Milano ${ }^{2} 1999$, S. 66-67. 
niam iudex Numerium Negidium Aulo Agerio condemnato. Si non paret, absolvito. den ist, dann, Richter, verurteile den Numerius Negidius dem Aulus Agerius auf so viel Geld, wieviel diese Sache wert sein wird. Wenn es sich nicht erweist, dann sprich ihn frei.

Lenel vermutet, dass die §pr.-2 von D. 13,7,9 auf den ersten Teil der intentio zu beziehen seien, also auf das: 'Si paret Aulum Agerium Numerio Negidio rem qua de agitur ob pecuniam debitam pignori dedissse'21. Während in $\S 1$ das Wort pecunia ausgelegt ${ }^{22}$ und in $\S 2$ pignus als Faustpfand definiert wird ${ }^{23}$, ließe sich das principium - wenn man nicht mit Kaser alternativ eine Kommentierung der Titelrubrik annehmen möchte ${ }^{24}$ - auf das rem ... pignori dare beziehen ${ }^{25}$ : Die Anwendung der actio pigneraticia in personam directa auf Rückgabe der Sache wird im Falle der Schuldtilgung auch dadurch nicht behindert, dass eine fremde Sache 'als Pfandsache' übergeben worden war ${ }^{26}$. Dies wird in D. 13,7,9,4 (Ulp. 28 ad ed.) - in Zusammenhang mit der Tilgung der Schuld - auch wieder aufgegriffen: 'Is quoque, qui rem alienam pignori dedit, soluta pecunia potest pigneraticia experiri ${ }^{27}$ - Auch der, welcher eine fremde Sache zum Pfand gegeben hat, kann nach Zahlung der Schuld die Klage aus dem Pfandrealvertrag erheben'.

21 Lenel, Palingenesia (supra, n. 18), S. 583 Anm. 2; Lenel, Edictum perpetuum (supra, n. 13), S. 254 .

22 'Non tantum autem ob pecuniam, sed et ob aliam causam pignus dari potest, veluti si quis pignus alicui dederit, ut pro se fideiubeat - Nicht nur wegen Geld(schulden), sondern auch wegen einer anderen Ursache kann ein Pfand bestellt werden, wie zum Beispiel wenn jemand irgendwem ein Pfand bestellt, damit er für ihn bürge'.

'Proprie pignus dicimus, quod ad creditorem transit, hypothecam, cum non transit nec possessio ad creditorem - Wir nennen eigentlich das 'Pfand', was auf den Gläubiger übergeht, und Hypothek, wenn nicht einmal der Besitz an der Pfandsache an den Gläubiger übergeht'.

24 Kaser, Pfandrecht, II (supra, n. 1), S. 199 Anm. 23.

25 Anders Kreller, Formula (supra, n. 15), S. 155: Wieso, fragt er, sollte Ulpian am Beginn des Formelkommentars die Konträrklage diskutieren? Deswegen ordnet Kreller D. 13,7,9 keiner Kommentierung der Formel, sondern jener des Edikts zu.

26 Vgl. so auch Schwarz, Konträrklagen (supra, n. 15), S. 138; F. Wubbe, Res aliena pignori data, De verpanding van andermans zaak in het klassieke romeinse recht, Leiden 196o, S. 128-129; Kaser, Pfandrecht, II (supra, n. 1), S. 223 und 331; A. Bürge, Retentio im römischen Sachenund Obligationenrecht, Zürich 1989, S. 189 Anm.11; F. Wieacker, Zur Verpfändung fremder Sachen, Tijschrift voor Rechtsgeschiedenis, 30 (1962), S. 58-76, 74.

27 Vgl. Schwarz, Konträrklagen (supra, n. 15), S. 138; M. Kaser, Das Römische Privatrecht, Erster Abschnitt: Das altrömische, das vorklassische und klassische Recht, München ${ }^{21971, ~ S . ~} 537$. 
Und selbst die Rückgabe der Früchte, die aus einer vom bösgläubigen Besitzer zum Pfand gegebenen Sache gezogen wurden, können von diesem gemeinsam mit der res aliena herausverlangt werden ${ }^{28}$.

Anders setzt der in D. 13,7,9pr. zugrunde gelegte Sachverhalt voraus, dass die Schuld noch nicht beglichen war: Eben darin, dass der Gläubiger Ego an der fremden Sache kein dingliches Pfandrecht erwerben konnte, bestand ja die Bedrohung seines Sicherungsinteresses. Deshalb war er ebenso wie für den Fall, dass der Pfandbesteller dolos gehandelt hat, mit der Möglichkeit versehen, gegen diesen eine Konträrklage zu erheben.

Mit dieser actio pigneraticia in personam contraria sind einige Fragen verbunden. Gegenstand der vorliegenden Untersuchung ist jene danach, worauf die Klage in D. 13,7,9pr. gerichtet war.

In den Lehrbüchern zum Römischen Recht wird diese Frage unterschiedlich beantwortet. Bei Jörs / Kunkel / Wenger findet sich die allgemeine Aussage, dass dem Pfandgläubiger eine actio contraria zustand, wenn 'die Pfandsetzung nicht den getroffenen Vereinbarungen und den nach Treu und Glauben berechtigten Anforderungen entsprach, so zB. wenn sich herausstellte, daß die Pfandsache nicht dem Verpfänder gehörte oder minderwertig war'29. Dies lässt das Ziel der Klage offen. Hausmaninger / Selb erkennen dieses in einem Schadenersatzanspruch und begründen dies wie folgt: 'Er [= der Pfandgläubiger] hatte doch aus der Pfandabrede kraft bona fides den Anspruch auf eine geeignete Pfandsache, die seinem Sicherungsbedürfnis entsprach'30. Benke / Meissel vertreten den Ansatz, dass der Pfandgläubiger unter Berufung auf den Pfandrealvertrag vom Pfandbesteller verlangen könne, 'dass er ihm an einer

28 Vgl. so D. 13,7,22,2 (Ulp. 31 ad ed.). Dies erfolgt nach Schanbacher, Konvaleszenz (supra, n. 1), S. 151 Anm. 808, 'wohl nicht zuletzt um die Sache wieder in die ursprüngliche Nähe zum Eigentümer gelangen zu lassen'; vgl. auch Wubbe, Res aliena (supra, n. 26), S. 150-151, der damit argumentiert, dass der Dieb die Früchte oder ihren Gegenwert nur dann herausverlangen könne, wenn der Berechtigte (der Eigentümer) nicht zum Vorschein komme.

29 P. Jörs / W. Kunkel / L. Wenger, Römisches Recht, Berlin-Göttingen-Heidelberg 31949, S. 224.

30 H. Hausmaninger / W. Selb, Römisches Privatrecht, Wien 92001, 223. Dies lässt sich so verstehen, dass der Pfandgläubiger bei Übergabe der Sache aufgrund der bona fides einen Anspruch auf eine Sache des Pfandgebers gehabt hätte, welcher daher nun schadenersatzpflichtig wird, aber auch so, dass der Pfandgläubiger als Vertragspartner einen Anspruch auf Bestellung eines tauglichen Pfandes erwirbt, wenn er eine res aliena übernommen hatte. 
Sache ein gültiges Pfandrecht einräumt'31. Wimmer begründet ebendiese Lösung der 'Klage aus dem Pfandvertrag, gerichtet auf die Bestellung eines Ersatzpfandes' damit, dass der Pfandrealvertrag nicht erfüllt worden ist, wenn eine fremde Sache hingegeben worden war $^{32}$.

Diese Interpretation findet sich schon bei Glück ${ }^{33}$ und Savigny ${ }^{34}$, aber auch in den Pandekten-Lehrbüchern des 19. Jh. wie etwa jenem von Baron ${ }^{35}$ oder von Dernburg, der für den Fall, dass 'eine fremde Sache als eigene verpfändet' wurde, folgerte: 'In derartigen Fällen kann der Pfandgläubiger mit der actio pigneraticia contraria nach seiner Wahl Zahlung seiner Forderung oder ein besseres Pfand verlangen'36. Auch bei Windscheid ist zu lesen, dass der Pfandbesteller 'zur Hingabe einer anderen Pfandsache' angehalten werden könne ${ }^{37}$. In all den genannten Lehrbüchern wird dies mit einem Verweis auch auf D. 13,7,9pr. ${ }^{38}$ begründet. Da diese Lösung dort aber gar nicht anklingt, ist zu überlegen, ob dies nicht Frucht jüngerer Interpretationen der Stelle ist: So

${ }^{31} \quad$ N. Benke / F.St. Meissel, Übungsbuch Römisches Sachenrecht, Wien ${ }^{1{ }_{2}} 2018$, S. 198. Diese Meinung wird in didaktischen Einführungswerken zum römischen Recht oft vertreten, so etwa von G. Klingenberg, Actiones, Einteilungen, Übersicht, Formelbeispiele, Wien 52012, S. 6; A. Pichler / E. Kossarz, 24 Musterexegesen zum römischen Recht, Wien 2018, S. 68-69; N. Benke / F.St. Meissel, Übungsbuch Römisches Schuldrecht, Wien 92019, S. 70-71; vgl. ebenso Ph. Klausberger, Pfandrealvertrag, in: Rechtsgeschichte und Römisches Recht, Studienwörterbuch, hrsg. von Th. Olechowski [und] R. Gamauf, Wien ${ }^{42020}$, S. 370-371, 371 .

32 M. Wimmer, Digestenexegese, Fälle mit Lösungen zum römischen Recht, Wien 32019, S. 36.

33 Ch.F. Glück, Ausführliche Erläuterung der Pandekten nach Hellfeld, Ein Commentar, 14/2, Erlangen ${ }^{2} 1843$, S. 65 : 'Leidet der Gläubiger durch Eviktion und Hauptmängel des vertragsmäßigen Pfandes, so kann er verlangen, daß ihm ein neues eingeräumt, auch daß ihm der, durch Versehen des Schuldners ihm sonst erwachsende Schaden vergütet werde'.

34 F.C. von Savigny, System des heutigen Römischen Rechts, 3. Band, Berlin 1840, S. 301-302 schreibt in Zusammenhang mit D. 13,7,1,2 (Ulp. 40 ad Sab.): 'Die pigneraticia contraria, die durch Zusage unzweifelhaft begründet ist, geht darauf, daß ein Pfand von gleichem Werth mit dem versprochenen goldenen Gefäß gegeben werde'. Daraus schließt er allgemein: 'Denn auch in anderen Fällen gilt diese Klage, wenn der Gläubiger aus Irrtum ein Pfand annimmt, das ihm keine hinreichende Sicherheit gewährt. Namentlich, wenn die verpfändete Sache in fremdem Eigenthum (...) ist'.

35 J. Baron, Pandekten, Leipzig ${ }^{8} 1893$, S. 50o: 'Er (= der Pfandbesteller) muss ihm, wenn er eine fremde Sache verpfändete, ein anderes Pfand bestellen'.

36 H. Dernburg, Pandekten, I, Berlin 31892, S. 69 o.

37 B. Windscheid, Lehrbuch des Pandektenrechts, Stuttgart 51879, S. 439: 'So ist der Verpfänder namentlich verpflichtet ... zur Hingabe einer anderen Pfandsache, wenn die hingegebene sich untauglich erweist oder nicht die zugesagten Eigenschaften hat'.

38 Ferner wird dort regelmäßig auf D. 13,7,16,1 (Paul 26 ad ed.) und D. 13,7,32 (Marc. 4 reg.) verwiesen; vgl. dazu sogleich unter 3, Anm. 79 . 
könnte das justinianische Recht hier verantwortlich zeichnen ${ }^{39}$. Nach einer Notiz in den frühen Auflagen des Lehrbuchs von Hausmaninger / Selb gewährt der Kaiser dem Pfandgläubiger die Möglichkeit, mit der Konträrklage die Bestellung einer neuen Pfandsache zu fordern, wenn die übergegebene Sache nicht adäquat ist, also zum Beispiel eine res aliena: Hier lässt Justinian dem Pfandgläubiger eine actio pigneraticia contraria zukommen, für den Fall, 'daß das Pfand nicht oder nicht mehr dem berechtigten Sicherungsbedürfnis des Pfandgläubigers entsprach, wie es sich aus der Pfandabrede nach Treu und Glauben ergab: Diese Klage ging auf Pfandbestellung'40. Die Konträrklagen nehmen im justinianischen Recht vielleicht eine prominentere Rolle ein, als in der Klassik ${ }^{41}$; welche Entscheidung Justinians Hausmaninger / Selb hinsichtlich der res aliena pignori data vor Augen haben, verschweigt das Lehrbuch allerdings ${ }^{42}$, das ab der fünften Auflage den Verweis

39 Vgl. auch den Hinweis bei Jörs / Kunkel / Wenger, Römisches Recht (supra, n. 29), S. 224, wonach die Konträrklage mindestens im justinianischen Recht gewährt wurde.

$40 \quad$ H. Hausmaninger/W. Selb, Römisches Privatrecht, Wien-Köln 1981, S. 277:'Der Realkontrakt wurde schließlich gänzlich verlassen, als Justinian dem Pfandgläubiger eine actio contraria für den Fall gab, daß das Pfand nicht oder nicht mehr dem berechtigten Sicherungsbedürfnis des Pfandgläubigers entsprach, wie es sich aus der Pfandabrede nach Treu und Glauben ergab: Diese Klage ging auf Pfandbestellung'. Ebenso steht es noch in der 4. Auflage 1987, S. 277 .

41 G. Provera, Linee generali di uno studio sui iudicia contraria, Studia et Documenta Historiae Iuris, 8 (1942), S. 113-135, 132-133 schreibt dem justinianischen Recht den 'Abschluss einer Entwicklung' hinsichtlich der iudicia contraria zu, welchen er auf deren Vertragscharakter bezieht, wie er sich etwa in der Haftung des Pfandrealvertragsgläubigers über doloses Verhalten hinaus manifestiere; dies erklärt sich allerdings aus Proveras genereller Ablehnung der Vorstellung von in ius konzipierten Konträrklagen, vgl. ebenda S. 120.

42 Denkbar wäre etwa C. 6,43,3,4 (Iust. A. Iohanni pp, a. 531), wo hinsichtlich vermachter oder fideikommissarisch überlassener Sachen festgehalten wird, dass der Erbe nicht darüber verfügen solle etwa mittels Verkauf oder Verpfändung. Wenn er eine solche Sache jedoch verkauft, so sei dieser Kaufvertrag ebenso ungültig wie ein an der Sache bestelltes Pfandrecht. In $§ 4$ der lex nun wird dem Pfandgläubiger in diesem Fall gegen den Erben eine actio pigneraticia contraria gewährt, da er eine fremde Sache zum Pfand bestellt hat. Dies entspricht dem Fall der Verpfändung einer 'res aliena: (...) creditori nihilo minus pigneraticia contraria actione adversus debitorem competente, ut ex omni parte omnique studio id, quod semper properamus, ad effectum perducatur, ut ultima elogia defunctorum legitimum finem sortiantur - (...) Dem Gläubiger aber steht nichts desto trotz gegen den Schuldner eine actio pigneraticia contraria zu, damit aus allen Stücken und mit jedem Fleiß das, was wir stets betreiben, erreicht werde, dass die letzte Äußerung der Verstorbenen zum rechtmäßigen Ende gelange.

Doch auch hier verschweigt die Quelle, worauf sich die Konträrklage richtet: der Pfandgläubiger kann nichts desto trotz (nihilo minus) die actio pigneraticia erheben. Diese Lösung für die Verpfändung einer fremden Sache unterscheidet sich zu dem vorher in C. 6,43,3,4 behandelten Fall des wissentlichen Kaufen der fremden Sache, wo der Käufer nur die Rückzahlung des Kaufpreises einklagen können soll, nicht aber eine allfällig 
auf Justinian ${ }^{43}$ dann auch ausspart und allgemein auf einen Schadenersatzanspruch rekurriert ${ }^{44}$.

Andererseits findet sich in der Glosse ein weiterer Hinweis, wie es zu der Interpretation gekommen sein könnte, dass der Pfandgläubiger die Bestellung eines Ersatzpfandes verlangen durfte, wenn ihm eine res aliena als Pfand überlassen worden war: In einer Marginalglosse zu Gl. interest zu D. 46,1,54 heißt es in Erläuterung der Frage, was denn das Interesse des bei Pfandrealvertragsschluss getäuschten Pfandgläubigers ausmache, lapidar: 'Pignus idoneum habere creditori interest $t^{45}$.

Schließlich hat die folgende Lösung mit $\S 458^{46}$ AB GB Einzug in das geltende österreichische Privatrecht gefunden ${ }^{47}$ :

Wenn der Wert eines Pfandes durch Verschulden des Pfandgebers, oder wegen eines erst offenbar gewordenen Mangels der Sache zur Bedeckung der Schuld nicht mehr zureichend gefunden wird, so ist der Gläubiger berechtigt, von dem Pfandgeber ein anderes angemessenes Pfand zu fordern.

Hier werden ein Schadenersatzproblem: der Pfandbesteller hat die Verschlechterung der Pfandsache verschuldet, und ein Gewährleistungsproblem: die

stipulierte Vertragsstrafe oder eben das Interesse. Das legt nahe, dass die actio pigneraticia auch in C. 6,43,3,4 auf Interesseersatz gerichtet ist. Zur Stelle vgl. auch W. Dajczak, Die Wendung bona fides im Schuldrecht der römischen Kaiserkonstitutionen, Orbis Iuris Romani, 6 (2000), S. 7-28, 26-27, der aber auf das unterschiedliche Klagsziel zwischen actio empti und actio pigneraticia in keiner Weise näher eingeht.

43 Auch die der Vertragspraxis der justinianischen Zeit zuordenbaren Papyri, welche eine Verpfändungsabrede enthalten wie zB. CPR 19,44 (400-599 n. Chr.) aus Alexandria oder PMich 11,507 (1. 3. 569 n. Chr.) aus Antinoopolis enthalten keine Klausel zum möglichen 'Austausch' der mangelhaften oder fremden Pfandsache.

44 H. Hausmaninger / W. Selb, Römisches Privatrecht, Wien 51989, S. 289.

45 So etwa C.F.F. Sintenis, Handbuch des gemeinen Pfandrechts, Halle 1836, S. 251 Anm. 2.

46 Vgl. ferner auch $\S 456$ Abs. 1 ABGB: 'Wird eine bewegliche Sache von jemandem verpfändet, dem sie nicht gehört und der darüber auch nicht verfügen kann, so hat der Eigentümer zwar in der Regel das Recht, sie zurückzufordern. In solchen Fällen, in denen die Eigentumsklage gegen einen rechtmäßigen und redlichen Besitzer abzuweisen ist, ( $\S 3_{67}$ und 368 ), ist er aber verpflichtet, den Pfandbesitzer schadlos zu halten oder das Pfand fahren zu lassen und sich mit dem Schadenersatzanspruch gegen den Verpfänder oder dritte Personen zu begnügen'. § 456 weist zwar den gleichen Ausgangssachverhalt wie D. 13,7,9pr. auf - der Verpfändung einer fremden Sache ohne Zustimmung des Eigentümers. In der Folge regelt die Bestimmung des АвG в aber die Rechtsposition des Eigentümers der verpfändeten Sache.

47 H. Hausmaninger / R. Gamauf, Casebook zum römischen Sachenrecht, Wien ${ }^{11}{ }_{2012}$, S. 239 verweisen so auch auf die $\S \S 456$ und 458 . 
Pfandsache weist einen Mangel auf, miteinander kombiniert. In beiden Fällen hat der Pfandgläubiger einen Austauschanspruch ${ }^{48}$. Da sowohl die verschuldete Verschlechterung (malitiose in pignore versari) als auch rechtliche Mängel wie zB. die mangelnde Eigentümerstellung des Pfandbestellers (rem alienam pignori dare) hiervon erfasst sind ${ }^{49}$, könnte D. 13,7,9pr. tatsächlich als Vorbild für diese Bestimmung fungiert haben ${ }^{50}$. Und nach $\S 45^{8}$ ABG в hat der Pfandgläubiger 'Anspruch darauf, daß ihm eine Sache übergeben wird, die hinsichtlich der Wertentwicklung und Verwertbarkeit der geschuldeten mangelfreien Sache gleichsteht ${ }^{51}$. Es ist aber weder methodisch vertretbar, noch sinnvoll, die Rechtsfolge von $\S 458$ ABG B ex post in das römische Recht zu transportieren, um auf ihrer Grundlage ein Digestenfragment auszulegen.

Es bleibt aber zu fragen, wieso in der pandektistischen und didaktischen Literatur stets auf die Fragmente aus D. 13,7 verwiesen wird, um die Einklagbarkeit der Ersatzpfandbestellung auch für das klassische römische Recht zu belegen. Hier gilt es, zu überprüfen, ob sich Ansätze für die 'Bestellung eines Ersatzpfandes', durchsetzbar mit der actio pigneraticia in personam contraria, schon im klassischen römischen Recht finden lassen.

Dies scheitert schon einmal wegen des Grundsatzes der Geldkondemnation im Formularprozess ${ }^{52}$ : Zur Leistung eines Ersatzpfandes konnte der Schuldner also nicht 'angehalten' bzw. verurteilt werden.

48 Gemäß J. Ofner, Der Ur-Entwurf und die Berathungs-Protokolle des österreichischen Allgemeinen Bürgerlichen Gesetzbuches, Band 1, Wien 1889 (ND Wien 1976), S. LI, lautet der $\S 258$ des 2 Teils, 8 . Hauptstück im Urentwurf des ABG B wie folgt: 'Nur für den Fall, wenn der Werth eines Pfandes ohne Verschulden des Gläubigers in der Folge nicht mehr zur Bedeckung der Schuldforderung zureicht; ist er berechtigt von dem Schuldner eine bessere Sicherstellung zu fordern: Zu dieser besseren Sicherstellung kann ein Dritter, der statt des Hauptschuldners ein Pfand gegeben hat, nur dann angehalten werden, wenn er sich eigens dazu verbindlich gemacht hat'. Bei erster Lesung der Bestimmung im Urentwurf wurde diese Berechtigung des Gläubigers, ein anderes Pfand zu fordern, in Frage gestellt. Dagegen wurde jedoch argumentiert, dass die Bestellung des Pfandes eine Bedingung für den Abschluss des Darlehens gewesen sei. Deshalb sei bei Wertminderung des Pfandes 'eine Bedingung des Hauptkontrakts, nämlich des Darlehens, nicht erfüllt, und der Gläubiger dadurch berechtigt, entweder die sogleiche Bezahlung der Forderung oder die Bestellung eines anderen, besseren Pfandes zu fordern'; zu alledem vgl. Ofner (Wien 1889), S. 296.

49 Vgl. dazu nur F.v. Zeiller, Commentar über das allgemeine bürgerliche Gesetzbuch für die gesammelten deutschen Erbländer der österreichisch-ungarischen Monarchie, Zweyter Band, Wien-Triest 1812, S. 269; Kommentar zum Allgemeinen Bürgerlichen Gesetzbuch, hrsg. von H. Klang, Wien ${ }^{2} 195$ o, S. 483 und Wien ${ }^{32016}$, S. 162 und 165.

$50 \quad$ Darin liegt wohl der Tatbestand, der auf D. 13,7,9pr. zurückgeht.

$51 \quad$ Ch. Huber, Probleme der Verjährung und des Einlösungsrechts bei Faustpfandbestellung durch einen Dritten, öJZ 1986, S. 193-199, 198.

$5^{2}$ Gai. Inst. 4.48: 'Omnium autem formularum, quae condemnationem habent, ad pecuniariam aestimationem condemnatio concepta est. itaque si corpus aliquod petamus, 
Aber auch wenn der Gläubiger auf die Bestellung eines Ersatzpfandes hätte klagen können, so müsste man konstruieren, dass dies nur indirekt bewirkt werden habe können, etwa, indem dem Schuldner ein vom Gläubiger sonst zu leistender Schätzungseid drohte. Dieser ist für die actio pigneraticia in personam contraria jedoch nicht belegt; allenfalls könnte man diese Möglichkeit sicut in ceteris bonae fidei iudiciiis ${ }^{53}$ erwägen ${ }^{54}$. Doch auch unter der Annahme,

velut fundum hominem vestem argentum, iudex non ipsam rem condemnat eum, cum quo actum est, sicut olim fieri solebat, sed aestimata re pecuniam eum condemnat - Die Verurteilung nach allen Klageformeln, die eine condemnatio beinhalten, ist auf die Schätzung eines Geldbetrages ausgerichtet. Wenn wir daher igendeine Sache verlangen, wie zum Beispiel eine Liegenschaft, einen Sklaven, ein Gewand oder Silber, dann verurteilt der Richter denjenigen, mit dem prozessiert worden ist, nicht auf die Sache selbst, so wie es einstmals üblich gewesen ist, sondern er verurteilt ihn nach Schätzung der Sache auf Geldleistung. Vgl. dazu auch A. Romano, Condanna 'in ipsam rem' e condanna pecuniaria nella storia del processo romano, Labeo, 28 (1982), S. 131-149; M. Pennitz, Der 'Enteignungsfall' im Römischen Recht der Republik und des Prinzipats, Eine funktionalrechtsvergleichende Problemstellung, Wien-Köln-Weimar 1991, S. 248-323; R. Zimmermann, The Law of Obligations, Oxford 1996, S. 771-772; K. Nehlsen von Stryk, Grenzen des Rechtszwangs, Zur Geschichte der Naturalvollstreckung, Archiv für die civilistische Praxis, 193 (1993), S. 529-555, 538; C.A. Cannata, Omnia iudicia absolutoria esse, in: Atti del Convegno 'Processo civile e Processo penale nell'esperienza giuridica del mondo antico, in memoria di Arnaldo Biscardi', Siena 2001, Milano 2011, S. 67-69, 68. Dass dessen ungeachtet im Eigentumsprozess ein 'vorrangiges Interesse an Naturalrestitution' erkennbar ist, legt M. Wimmer, Besitz und Haftung des Vindikationsbeklagten, Köln-Weimar-Wien 1995, S. 113-121 dar.

53 So etwa D. 13,6,3,2 (Ulp. 28 ad ed.); ähnlich D. 12,3,5 pr. (Marc. 4 reg.); vgl. dazu insbes. Pennitz, Der 'Enteignungsfall' (supra, n. 52), S. 272-274 und allgemein M. Kaser / K. Hackl, Das Römische Zivilprozessrecht, München 2 1996 , S. 297 u. 340; L. Winkel, Specific performance in Roman law, in: The right to specific performance, The historical development, hrsg. von J. Hallebeek / H. Dondorp, Antwerpen e.a. 2010, S. 9-20, 11. Zur Frage, ob die verallgemeinernde Aussage in D. 13,6,3,2 (Ulp. 28 ad ed.) Produkt kompilatorischer oder redaktioneller Eingriffe der justinianischen Juristen war, vgl. S.A. Cristaldi, La sigla $n r$ nella formula in ius dell'actio depositi riportata da Gaio (Inst. 4.47, difesa di un dato testuale, zss romAbt 133 (2016), S. 135-175, 16o Anm. 103 mit Literaturangaben.

54 Auch wird für die in ius konzipierte actio depositi contraria der Schätzungseid vielleicht indirekt angedeutet, vgl. D. 16,3,5 pr. (Ulp. 30 ad ed.): 'Ei, apud quem depositum esse dicetur, contrarium iudicium depositi datur, in quo iudicio merito in litem non iuratur: non enim de fide rupta agitur, sed de indemnitate eius qui depositum suscepit - Dem, bei welchem ein Gegenstand in Verwahrung sein soll, wird die Konträrklage zugestanden, in welcher mit Recht nicht in litem geschworen wird: denn dort wird nicht wegen eines Treuebruchs geklagt, sondern wegen der Schadloshaltung dessen, der das Verwahrgut übernommen hat'. Aufgrund der Argumentation mit der fides rupta lässt sich das Fragment wohl auf die in ius konzipierte actio depositi directa beziehen, vgl. Lenel, Edictum perpetuum (supra, n. 13), S. 289; T. Walter, Die Funktionen der actio depositi, Berlin 2013, S. 284; Cristaldi, La sigla (supra, n. 53), S. 160-161. J.D. Harke, Der Eid im klassischen römischen Privat- und Zivilprozessrecht, Berlin 2013, S. 173, schließt den Schätzungseid in Zusammenhang mit Konträrklagen aus. 
dass der mittels actio pigneraticia contraria Beklagte durch des Klägers iusiurandum in litem zur naturalen Befriedigung seines Gegners bewegt werden hatte können, müsste sich diese auf die Verschaffung einer neuen Pfandsache beziehen und nicht auf das restituere / reddere einer geschuldeten Sache ${ }^{55}$, den typischen Anwendungsfall des Schätzungseids ${ }^{56}$.

Somit bleibt für eine naturale Befriedigung durch den Schuldner bloß die allgemeingültige Variante, dass der Pfandschuldner eine Verurteilung vielleicht dadurch verhindern hätte können, dass er post litem contestatam ein adäquates Ersatzpfand bestellte und der iudex dies nach den Grundsätzen der bona fides als ausreichend qualifiziert hätte und von einer condemnatio Abstand genommen. Doch dies ist für den Pfandrealvertrag, wie noch zu zeigen sein wird ${ }^{57}$, nicht belegt.

Belegt ist dies hingegen für den mit der actio conducti belangten Vermieter in D. 19,2,9pr. (Ulp. 32 ad ed.):

Si quis domum bona fide emptam vel fundum locaverit mihi isque sit evictus sine dolo malo culpaque eius, Pomponius ait nihilo minus eum teneri ex conducto ei qui conduxit, ut ei praestetur frui quod conduxit licere. Plane si dominus non patitur et locator paratus sit aliam habitationem non minus commodam praestare, aequissimum esse ait absolvi locatorem.

Wenn irgendwer ein Haus gutgläubig gekauft hat oder eine Liegenschaft, und sie mir vermietet hat und diese ohne Vorsatz oder Fahrlässigkeit (des Vermieters) evinziert worden ist, sagt Pomponius, dass um nichts weniger jener aus dem Mietvertrag dem hafte, der gemietet hat, sodass er ihm einsteht für die ungestörte Nutzung dessen, was er gemietet hat. Freilich, wenn der (neue) Eigentümer das nicht billigt und der Vermieter bereit wäre, eine andere Wohnung, die nicht minder adäquat ist, zur Verfügung zu stellen, so sagt er [i.e. Pomponius], dass es äußerst billig sei, dass der Vermieter freigesprochen werde.

Zum Problem der Naturalrestitution bei reddere-Klagen vgl. Wieacker, Zur Verpfändung (supra, n. 26), S. 72; zum Schätzungseid im Eigentumsstreit vgl. Pennitz, Der 'Enteignungsfall' (supra, n. 52), S. 301-306.

56 Vgl. dazu nur Harke, Der Eid (supra, n. 54), S. 177. Für den Pfandrealvertrag ist zu ergänzen, dass der Schätzungseid keine ausreichende motivatorische Kraft für eine Ersatzpfandbestellung entwickelt hätte, da er wohl regelmäßig auf den Wert der gesicherten Forderung hätte lauten müssen, vgl. dazu auch I. Reichard, Die Frage des Drittschadensersatzes im klassischen römischen Recht, Köln-Wien-Weimar 1993, S. 200.

Vgl. dazu unten 3 am Ende. 
Gemäß der Meinung des Juristen Pomponius ${ }^{58}$ soll der Vermieter nach Eviktion der Bestandsache durch Bereitstellen einer nicht minder geeigneten Wohnung freigesprochen werden: 'plane si ... locator paratus sit aliam habitationem non minus commodam praestare, aequissimum esse ait absolvi locatorem'59. Hier liegt eine Einzelfallentscheidung des Pomponius vor, der an die aequitas

$5^{8}$ Th. Mayer-Maly, Locatio conductio, Eine Untersuchung zum klassischen römischen Recht, Wien 1956, S. 156, schreibt diese Entscheidung Labeo zu, die Pomponius zu einer Regel habe ausweiten wollen. Daher ergänzt er: 'aequissimum esse $<$ Labeo $>$ ait absolvi locatorem'. Dies sei aber nach M. Kaser, Periculum locatoris, zss romAbt 74 (1957), S. 155-200, 168 Anm. 43 'nicht begründet'. Lenel ordnet das Fragment als Nr. 134 dem Ediktskommentar des Pomponius zu; ebenso Mayer-Maly, Locatio conductio (supra), S. 202 und E. Stolfi, Studi sui 'Libri ad Edictum' di Pomponio, II: Contesti e pensiero, Milano 2001, S. 182 u. 184. Zu Pomponius als Quelle für Ulpian vgl. T. Honoré, Ulpian, Oxford 22002, S. 132.

59 Der plane si - Satz wird von Kaser, Periculum locatoris (supra, n. 58), S. 168 und M. Kaser, Römisches Privatrecht, München 2 ${ }^{1971}$, S. 567 Anm. 44, gegen die überwiegende Mehrheit für klassisch gehalten; vgl. dazu Stolfi, Studi (supra, n. 58), p.183-184. Dies kann jedoch nicht unbedenklich für die vergleichbare Lösung in D. 19,2,6opr. (Lab. 5 a Iavol. epit.) hingenommen werden: 'Cum in plures annos domus locata est, praestare locator debet, ut non solum habitare conductor ex calendis illis cuiusque anni, sed etiam locare habitatori si velit suo tempore possit. Itaque si ea domus ex kalendis Ianuariis fulta in kalendis Iuniis permansisset, ita ut nec habitare quisquam nec ostendere alicui posset, nihil locatori conductorem praestaturum, adeo ut nec cogi quidem posset ex kalendis Iuliis refecta domu habitare, nisi si paratus fuisset locator commodam domum ei ad habitandum dare - Wenn ein Haus auf mehrere Jahre vermietet ist, dann muss der Vermieter dafür einstehen, dass der Mieter nicht nur seit jenen Kalenden dieses Jahres an dort wohnen kann, sondern dem Mieter auch dafür einstehen, dass er, wenn er will, in dieser Zeit vermieten kann. Wenn daher dieses Haus von den Kalenden des Jänner an bis zu den Kalenden des Juni gestützt bleibt, so dass niemand darin wohnen oder es einem Dritten (zur Vermietung) zeigen kann, dann muss der Mieter dem Vermieter für keinen Zins einstehen, so dass er nicht einmal gezwungen werden kann, von den Kalenden des Juli an in dem renovierten Haus zu wohnen, wenn nicht der Vermieter bereit ist, ihm ein geeignetes Haus zum Bewohnen zur Verfügung zu stellen'.

Der nisi-Satz wurde von M. Eisele, Beiträge zur Erkenntnis der Digesteninterpolationen, zss romAbt 10 (1889), S. 296-322, 312-313 der Interpolation verdächtigt. So liege in D. 19,2,6o das Hauptaugenmerk des Mieters ja nicht auf dem Gebrauch, sondern auf der Untervermietung der Wohnung: Wenn der nisi-Satz eine Ausnahme zu der Feststellung formuliert, dass der Mieter nach erfolgter Renovierung nicht in das Haus einziehen müsse, so würde dies bedeuten: Er kann dazu gezwungen werden, wenn es eine Ersatzwohnung gab, vgl. Eisele, Beiträge (supra, n. 59), S. 312; Mayer-Maly, Locatio conductio (supra, n. 58), S. 156, lässt den nachklassischen Herausgeber der Epitome Iavolens dafür verantwortlich zeichnen, Eisele, Beiträge (supra, n. 59), S. 312, vermutet einen justinianischen Einschub; vgl. dazu auch Stolfi, Studi (supra, n. 58), S. 183-184 Anm. 200. 
des Richters ${ }^{60}$ appelliert ${ }^{61}$. Dies ergibt sich aus dem Verb absolvere im Gegensatz zur dem Vermieter drohenden condemnatio: Die Ersatzwohnung wird also erst nach litis contestatio angeboten ${ }^{62}$.

Festzuhalten ist, dass der Mieter keinen Anspruch auf die Beschaffung einer Ersatzwohnung hat. Vielmehr kann der Vermieter ausnahmsweise eine ihm drohende Verurteilung abwehren, indem er freiwillig die adäquate Ersatzwohnung anbietet ${ }^{63}$, deren Annahme eine Obliegenheit des Mieters darstellt;

6o Dies ist durchaus nicht unproblematisch, da, wie F. Pringsheim, Aequitas und bona fides, in: Gesammelte Schriften, I, Heidelberg (1961), S. 154-172, 159, festhält, die aequitas 'ein Werkzeug des prätorischen Rechts' darstellt, während sie dem iudex 'ganz ferngehalten werden' muss (S.163). Vielmehr bezeichne die aequitas iudicis sein Urteilen auf Grundlage der bona fides. Pringsheim erklärt dies daraus, dass die Begriffe aequitas und bona fides vertauscht worden waren: '(...) der Vermieter, der nach Eviktion dem Mieter eine andere geeignete Wohnung gestellt hat, wird nicht deswegen absolviert, weil er gemäß der bona fides gehandelt hat, sondern weil dies aequissimum ist' (S. 170).

$61 \quad$ Ulpian gebraucht die Phrase aequissimum esse 8omal, vgl. dazu die Belege bei T. Honoré, Ulpian, Oxford 1982, S. 79 Anm. 669-671 und Honoré, Ulpian (supra, n. 58), S. 61 Anm. 336. Auch wenn daher die Wertung, dass es äußerst recht und billig wäre, den Vermieter freizusprechen, dem Ulpian selbst zugerechnet werden könnte, ist darauf zu verweisen, dass in D. 19,2,9pr. das aequissimum esse in indirekter Rede, abhängig von ait steht, wie es für Ulpian ansonsten noch in drei weiteren Texten belegt ist: Noch einmal für Pomponius in D. 4,6,28,6 (Ulp. 12 ad ed.): 'aequissimum esse Pomponius ait', ferner für Iulian in D. 7,1,13,3 (Ulp. 18 ad Sab.): 'Iulianus ... scribit aequissimum esse'; und für Papinian in D. 4,8,21,5 (Ulp. 15 ad ed.): 'Papinianus ait ... aequissimum esse'. Dies legt nahe, dass Ulpian hier wie in D. 19,2,9pr. die betreffenden älteren Juristen zitiert hat; vgl. dazu auch Stolfi, Studi (supra, n. 58), S. 184 mit Anm. 202.

62 Anderes könnten die Übersetzungen wie jene von K. Luig in: Corpus Iuris Civilis, III (supra, n. 7), S. 557 oder H. Hausmaninger / R. Gamauf, Casebook zum römischen Vertragsrecht mit einem Abschnitt zum Schadenersatzrecht der lex Aquilia, Wien 72012, S. 259, vermuten lassen, wenn dort locatorem absolvi vom 'Klage abweisen' widergegeben wird. Dies entgeht auch dem gestrengen Blick von Th. Mayr-Maly, Rez. O. Behrends / R. Knütel / B. Kupisch / H.H. Seiler (Hgg.), Corpus Iuris Civilis, III: Digesten 11-20, Heidelberg 1999, in: zss romAbt 119 (2002), S. 441-444, 444, der Luigs Übersetzung von sine dolo malo culpaque eius mit 'ohne daß Kenntnis oder vorwerfbare Unkenntnis des Vermieters hinsichtlich des fehlerhaften Eigentums vorliegen' als zu eng gefasst tadelt. B. Frier, in: The Digest of Justinian, English Translation, 2, hrsg. von A. Watson, Philadelphia 1985, S. 101, bewegt sich mit 'released from any further obligation' sehr weit weg vom prozessualen Kontext, in dem das locatorem absolvi zu lesen ist. Vielmehr ist hier zu folgen der Übersetzung von Otto / Schilling / Sintenis, Corpus Iuris Civilis (supra, n. 6), S. 432 mit: 'den Verpächter freizusprechen'. Deutlich hier auch die spanische Übersetzung von H. Ankum, Pomponio, Juliano y la responsabilidad del vendedor por evicción con la actio empti, Revue Internationale des Droits de l'Antiquité, 3eme série, 39 (1992), S. 57-84, 83 (= ders, Nueva antología romanística, Madrid-Barcelona-Buenes Aires-Sao Paolo 2014, S. 187-216), S. 215: 'que en tal caso el locator sea absuelto por el juez'.

63 Vgl. dazu auch D. Medicus, Id quod interest, Studien zum römischen Recht des Schadensersatzes, Köln-Graz 1962, S. 10o: Den locator trifft keine Rechtspflicht, er hat vielmehr eine 
ob es zu einem Freispruch kommt, ist jedoch der aequitas iudicis anheimgestellt ${ }^{64}$.

Es ist fraglich, ob diese Entscheidung hinsichtlich der locatio conductio auch auf andere bonae fidei iudicia wie die actio pigneraticia ${ }^{65}$ angewandt werden kann. Zweifellos ist denkbar, dass der Richter gemäß dem Grundsatz omnia (bonae fidei) iudicia absolutoria sunt ${ }^{66}$ den debitor aus D. 13,7,9pr. freispricht, wenn dieser bereit ist, ein Ersatzpfand zu stellen, das nicht minder geeignet ist als die fremde Sache ${ }^{67}$.

Die vorliegende Untersuchung aber widmet sich gar nicht der Frage einer möglichen absolutio des Schuldners, welcher apud iudicem ein neues Pfand bestellt hat, sondern jener danach, ob - wie in der pandektistischen und Lehrbuch-Literatur behauptet wird - der Schuldner aus dem Pfandrealvertrag zu einer solchen Leistung verpflichtet ist (facere oportet). Dazu ist es notwendig, in einem nächsten Schritt den Blick auf weitere Fragmente zum Problem des rem alienam pignori dare zu lenken.

\section{3}

\section{Res aliena pignori data und Interesseersatz}

Der Pfandrealvertrag kommt durch Übergabe der Pfandsache und die Abrede, dass diese als Sicherheit für ein Schuldverhältnis dienen soll, zustande ${ }^{68}$. Wie

Ersetzungsbefugnis; ebenso Pichler / Kossarz, 24 Musterexegesen (supra, n. 31), S. 187 Anm. 27.

64 Anders wäre die Situation, wenn die Formel eine Arbiträrklausel enthalten hat, mittels derer der Richter ein iussum de restituendo erteilen musste. Ein solches ist für die bonae fidei iudicia jedoch nicht belegt, sieht man von den umstrittenen Buchstaben 'NR' der gaianischen Überlieferung der actio depositi in ius concepta in Gai. Inst. 4.47 ab; vgl. dazu und für die Vereinbarkeit von Arbiträrklausel und bonae fidei iudicium Cristaldi, La sigla (supra, n. 53), S. 166-172; zustimmend für die in ius konziperte Verwahrungsklage etwa M. Kaser / R. Knütel / S. Lohsse, Römisches Privatrecht, München ${ }^{212017}$, S. 463.

65 Zur Frage, ob der Pfandrealvertrag auch eine in ius konzipierte und auf die bona fides rekurrierende Formel enthalten hat, siehe unten 4.

66 Vgl. Gai. Inst. 4.114. Mit Cannata, Omnia iudicia (supra, n. 52), p, S. 67-69, ist der Satz als 'principio del processo formulare' zu qualifizieren; zustimmend C. Buzzacchi, Omnia iudicia absolutoria, il fecondo paradosso del processo civile romano, in: Il giudice privato nel processo civile romano, Omaggio ad Alberto Burdese, hrsg. von L. Garofalo, Padua 2012, S. 1-23, 12.

$67 \quad$ Zu dem Grundsatz 'omnia iudicia absolutoria sunt' als Komponente für die Ausformung der obligatio als Basis subjektiver Rechte vgl. ferner R. Santoro, Omnia iudicia absolutoria esse, in: Atti del Convegno 'Processo civile e Processo penale nell'esperienza giuridica del mondo antico', in memoria di Arnaldo Biscardi, Siena 2001, Milano 2011, S. 259-263.

68 Vgl. Brauckmann, Pignus (supra, n. 19), S. 43; M.-Th. Fögen, Vom Typenzwang des römischen Rechts am Beispiel des Realvertrags, in: Spuren des römischen Rechts, Festschrift für 
schon angeführt, ist dies von der Eigentümerstellung des Pfandgebers unabhängig69: Nach Tilgung der Schuld ${ }^{70}$ konnte sich der Pfandbesteller der actio pigneraticia in personam directa bedienen, um die res aliena vom Gläubiger heraus zu verlangen. Aber nur an einer Sache, die zum Zeitpunkt der Pfandbestellung (tunc) zumindest in bonis ${ }^{71}$ des Pfandbestellers stand, kann dieser ihm gemäß dem Wortlaut der intentio der actio Serviana ein dingliches Recht einräumen:'rem tunc, cum conveniebat, in bonis Lucii Titii fuisse'72. Es ist also zweifellos vordringliches Interesse des Pfandgläubigers, eine solche Sache auch zu erhalten.

In D. 13,7,36,1 (Ulp. 11 ad ed.), einer Stelle aus dem ulpianischen Ediktskommentar zur actio de dolo, wird laut Sachverhalt dem Pfandgläubiger wissentlich eine fremde oder, ohne diesbezüglichen Hinweis, eine bereits belastete Sache verpfändet:

Sed et si quis rem alienam mihi pignori dederit sciens prudensque vel si quis alii obligatam mihi obligavit nec me de hoc certioraverit, eodem

Bruno Huwiler zum 65. Geburtstag, hrsg. von P. Pichonnaz / N.P. Vogt / St. Wolf, Bern 2007, S. 249-265, 251; A. Wegmann, Obligatio re contracta, Tübingen 2017, S. 209.

69 Wubbe, Res aliena (supra, n. 26), S. 129 verweist darauf, dass auch bei den Realverträgen commodatum und depositum die Eigentümerstellung der übergebenden Partei dem Zustandekommen des Vertrages nicht hinderlich war, vgl. dazu D. 13,6,15 (Paul. 29 ad ed.); D. 13,6,16 (Marcell. 5 dig.) und D. 16,3,1,39 (Ulp. 30 ad ed.).

70 In D. 13,7,9pr. ist dieses Stadium der Tilgung der Schuld noch nicht erreicht: Der Pfandgläubiger bemerkt, dass er eine fremde Sache erhalten hat und reagiert.

71 Gemäß dem Ergebnis der Arbeiten H. Ankum / M. Van Gessel-de Roo / E. Pool, Die verschiedenen Bedeutungen des Ausdrucks in bonis alicuius esse / in bonis habere, Teil I, zss romAbt 104 (1987), S. 154-436; Teil II, zss romAbt 105 (1988), S. 334-435; Teil III, zsS romAbt 107 (1990), S. 155-215, ist in bonis esse mit 'bonitarischem Eigentum' gleichzusetzen; zum in bonis esse als Ersitzungsbesitz vgl. P. Apathy, Verpfändung durch einen Nichteigentümer, IVRA, 35 (1984), S. 1-15. Unentschieden scheinen Kaser / Knütel / Lohsse, Römisches Privatrecht (supra, n. 64), S. 183, die zwar 'in bonis esse' als prätorisches oder ziviles Eigentum verstehen, allerdings darauf verweisen, dass 'der Pfandgläubiger keinen dinglichen Schutz erwirbt, wenn der Verpfänder nicht einmal Ersitzungsbesitzer ist'. B. Sirks, Die Bedeutung von in bonis in der actio Serviana, zss romAbt 136 (2019), S. 84-110 vertritt, dass hinsichtlich Provinzialland gutgläubiger Besitz als in bonis esse interpretiert werden kann; ebenso W.J. Zwalve / B. Sirks, Grundzüge der europäischen Privatrechtsgeschichte, Einführung und Sachenrecht, Wien-Köln-Weimar 2012, S. 407 Anm. 16.

72 Die Formel der actio Serviana nach Lenel, Edictum perpetuum (supra, n. 13), S. 494-495 lautet: 'Si paret inter Aulum Agerium et Lucium Titium convenisse, ut ea res qua de agitur Aulo Agerio pignori esset propter pecuniam debitam, eamque rem tunc, cum conveniebat, in bonis Lucii Titii fuisse eamque pecuniam neque solutam neque eo nomine satisfactum esse neque per Aulum Agerium stare quo minus solvatur, nisi ea res arbitrio iudicis restituetur, quanti ea res erit, tantam pecuniam iudex Numerium Negidium Aulo Agerio condemnato, si non paret absolvito'. 
crimine plectetur. plane si ea res ampla est et ad modicum aeris fuerit pignerata, dici debebit cessare non solum stellionatus crimen, sed etiam pigneraticiam et de dolo actionem, quasi in nullo captus sit, qui pignori secundo loco accepit.

Aber wenn irgendjemand mir wissentlich und willentlich eine fremde Sache zum Pfand gegeben hat oder eine einem anderen bereits verpfändete Sache, und mich darüber nicht in Kenntnis setzte, so wird er wegen derselben Straftat bestraft werden. Wenn die Sache aber wertvoll ist und für nur einen mäßigen Geldbetrag verpfändet worden ist, dann wird gesagt werden müssen, dass nicht nur die Straftat wegen Stellionats nicht vorliegt, sondern auch die Klage aus dem Pfandrealvertrag und die Arglistklage, weil der in keiner Weise betrogen worden ist, welcher im zweiten Rang eine Sache zum Pfand angenommen hat.

Der Text nennt wohl ursprünglich die actio de dolo als das dem Pfandgläubiger zukommende Rechtsmittel, das 'später von der actio pigneraticia abgelöst wurde $^{73}$. Ulpian prüft die Anwendbarkeit des crimen stellionatus ${ }^{74}$, und verneint diese für Variante 2, die Verpfändung einer bereits belasteten Sache, wenn aufgrund ihres Wertes ausreichende Deckung der Forderung gegeben ist. Ebenso ausgeschlossen sei hier die Anwendbarkeit von actio de dolo und actio pigneraticia $^{75}$. Dies gilt aber wohl nicht in Variante 1, bei der Verpfändung einer fremden Sache: Hier war die actio pigneraticia contraria jedenfalls kompetent ${ }^{76}$.

Ähnlich verhält es sich etwa in D. 13,7,32 (Marc. 4 reg.): 'Cum debitore, qui alienam rem pignori dedit, potest creditor contraria pigneraticia agere, etsi

73 d'Ors, Observaciones (supra, n. 13), S. 19o; Kaser, Pfandrecht, II (supra, n. 1), S. 223. Schwarz, Konträrklagen (supra, n. 15), S. 139-140 vermutet, dass der Ulpiantext auch die actio de dolo genannt habe, ist aber auch von der Erwähnung der Konträrklage überzeugt. Stein, Fault (supra, n. 12), S. 135-136 vermutet aufgrund des Nebeneinanders von actio de dolo und actio pigneraticia in personam contraria, dass hier Interpolationen anzunehmen seien: Ulpian müsse die Konträrklage genannt und die actio de dolo verneint haben, mit der der Text ursprünglich befasst gewesen sein könnte.

74 Auch im principium von D. 13,7,36pr. wird das Vorliegen des crimen stellionatus bejaht, vgl. dazu unten unter 5 .

75 Hier könnte eine Kontroverse ausgelassen worden sein, vgl. Kaser, Pfandrecht, II (supra, n. 1), S. 224 Anm. 166. Die Betonung, dass der Pfandbesteller sciens prudensque eine fremde Sache zum Pfand übergeben hat, weist darauf hin, dass hier wohl ursprünglich nur die actio de dolo diskutiert worden war, vgl. auch E. Sciandrello, Ricerche in tema di iudicia contraria, Napoli 2017, S. 128-129.

76 Zum Text vgl. auch R. Mentxaka, Stellionatus, Bulletino dell'Istituto di Diritto Romano, 91 (1988), S. 277-335, 288-295. 
solvendo debitor sit - Der Gläubiger kann den Schuldner, der eine fremde Sache zum Pfand bestellt hat, klagen, obwohl der Schuldner zahlungsfähig ist'.

Auch wenn der Pfandbesteller zahlungsfähig war, hat der Pfandgläubiger vor Fälligkeit eine actio pigneraticia in personam contraria 'auf Schadenersatz wegen ausgebliebener Sicherung; nicht darauf kommt es an, ob der Schuldner jetzt zahlungsfähig ist, sondern ob er es bei Fälligkeit sein wird'77. Durch eine Verurteilung aus dem iudicium contrarium hat der Schuldner auch keine Infamie-Folgen $^{78}$ zu fürchten ${ }^{79}$. Wie in D. 13,7,9pr. wird hier nicht gesagt, dass der Pfandbesteller vorsätzlich eine fremde Sache hingegeben hat.

Dies trifft auch auf D. 13,7,16,1 (Paul 29 ad ed.) zu ${ }^{80}$ :

Contrariam pigneraticiam creditori actionem competere certum est ${ }^{81}$ : proinde si rem alienam vel alii pigneratam vel in publicum obligatam dedit, tenebitur, quamvis et stellionatus crimen committat. sed utrum ita demum, si scit, an et si ignoravit? et quantum ad crimen pertinet, excusat

77 Schwarz, Konträrklagen (supra, n. 15), S. 142; ebenso Stein, Fault (supra, n. 12), S. 133. Beide verweisen auf die Aktivlegitimation des Pfandgläubigers zur actio furti trotz Zahlungsfähigkeit des Schuldners in D. 47,2,12,2 (Ulp. 29 ad Sab.).

78 Zum einen ist die Verurteilung aus der actio pigneraticia in personam nicht mit Infamie bedroht, zum anderen ist dies etwa auch bei den actiones mandati und depositi, welche bei Verurteilung aufgrund der actiones directae die Folgen der Infamie zeitigen, für die Konträrklagen ausgeschlossen, vgl. dazu allgemein D. 3,2,6,7 (Ulp. 6 ad ed.); zum Fall der Infamie bei Verurteilung aus der aus dem Titel des Bürgenregresses eingebrachten actio mandati contraria nach D. 3,2,6,5 (Ulp. 6 ad ed.) vgl. Ph. Scheibelreiter, Schande, in: Reallexikon für Antike und Christentum, xxIx (2019), S. 699-726, 709 mit weiteren Nachweisen.

79 Wenn I. Kroppenberg, Die Insolvenz im klassischen römischen Recht, Köln-Wien-Weimar 2001, S. 500, die Lösung in D. 13,7,32 daraus erklärt, dass dem Gläubiger die dingliche Klage eben lieber sei als die nicht konkursfeste actio in personam, und andererseits damit der Schuldner weiterhin am Wirtschaftsleben teilnehmen könnte, wenn die dingliche Sicherung bestellt würde, so hat sie in der Sache zweifellos Recht; zugleich postuliert sie aber, dass gemäß D. 13,7,32 auf Bestellung eines Pfandes geklagt werden könne und nicht auf Schadenersatz aus dem Pfandrealvertrag. Davon ist aber in der Stelle nichts zu lesen.

8o Zu allen drei Stellen als Beleg dafür, dass für die Anwendbarkeit der actio pigneraticia contraria ein dolus des Pfandgebers einer res aliena nicht vorausgesetzt war vgl. G. Provera, Una riforma giustininea in tema di iudicia contraria, in: Studi Solazzi, Napoli 1948, S. 345-356, 345-347; Stein, Fault (supra, n. 12), S. 128-131.

$81 \quad \mathrm{Zu}$ diesem der Interpolation verdächtigten Einleitungssatz vermutet etwa O. Lenel, Die cura minorum der klassischen Zeit, zss romAbt 35 (1914), S. 129-213 einen Einschub, denn: 'Auch mir erregt diese unnötig emphatische Versicherung Anstoß'. Der Sinn dieses Einschubs sei es vielmehr gewesen, die beiden Paragraphen D. 13,7,16 pr. und 1 abzugrenzen, welche auch im Ediktskommentar des Paulus voneinander separiert waren und nur in der Überlieferung aneinandergereiht worden seien, vgl. Lenel, Die cura minorum (supra), S. 172; ähnlich argumentiert auch Kreller, Pfandedikt (supra, n. 15), S. 156 Anm. 52. 
ignorantia: quantum ad contrarium iudicium, ignorantia eum non excusat, ut Marcellus libro sexto digestorum scribit. sed si sciens creditor accipiat vel alienum vel obligatum vel morbosum, contrarium ei non competit.

Es ist sicher, dass dem Gläubiger die Konträrklage aus dem Pfandrealvertrag zusteht: Daher wird haften, wer eine fremde oder eine einem anderen verpfändete Sache oder eine, die dem Gemeinwesen verpflichtet ist, zum Pfand gibt, obwohl er auch den Straftatbestand des Stellionats erfüllt. Aber haftet er nur, wenn er es weiß, oder auch, wenn er es nicht wusste? Was den Straftatbestand betrifft, entschuldigt ihn das Nichtwissen: Was aber die Konträrklage aus dem Pfandrealvertrag betrifft, so entschuldigt ihn das Nichtwissen nicht, wie Marcellus im sechsten Buch der Digesten schreibt. Wenn der Gläubiger aber wissentlich eine fremde Sache annahm oder eine verpfändete oder eine mangelhafte, dann steht ihm die Konträrklage aus dem Pfandrealvertrag nicht zu.

Paulus differenziert hinsichtlich der Klagemöglichkeiten auch des creditor, qui rem alienam pignori accepit: Während für das crimen stellionatus (und auch die actio de dolo $)^{82}$ Wissentlichkeit (si scit) des Schuldners Voraussetzung waren, konnte die actio pigneraticia auch angestrengt werden, wenn der debitor unwissend gehandelt hat: 'ignorantia eum non excusat'83.

Auch in C. 8,15,6 (Diocl./Max. a. 293), wo eine Mutter den zuvor ihren Söhnen geschenkten fundus an Dritte verpfänden möchte, wird sie aus dem iudicium contrarium verpflichtet (se contrario pigneraticio obligavit iudicio), da die Verpfändung unwirksam war ${ }^{84}$ :

Imp. Diocl. / Max. AA et cC Zosimo.

Quae praedium in filios se titulo donationis translatum creditori suo dat pignori, se magis contraria pigneraticia obligavit iudicio, quam quicquam dominis nocet, cum Serviana etiam actio declarat evidenter iure pignoris teneri non posse, nisi quae obliganti in bonis fuerint, et per alium alienam rem invito domino pignori obligari non posse certissimum est [a. 293].

82 Vgl. Schwarz, Konträrklagen (supra, n. 15), S. 144.

83 Vgl. dazu Mentxaka, Stellionatus (supra, n. 76), S. 285-288.

84 Vgl. dazu den Satz: 'per alium alienam rem invito domino pignori obligari non posse certissimum est', und dazu H. Ankum, Spätklassische Problemfälle bezüglich der Verpfändung einer res aliena, in: Festschrift für Rolf Knütel zum 7o. Geburtstag, hrsg. von H. Altmeppen / I. Reichard / M.J. Schermaier, Heidelberg 2009, S. 35-44, 36. 
Die Kaiser Diokletian und Maximian an Zosimos.

Eine Frau, die eine aus dem Titel der Schenkung an die Söhne übertragene Liegenschaft ihrem Gläubiger zum Pfand gegeben hat, verpflichtet sich eher aus der konträren Klage als dass irgendetwas den Eigentümern schaden könnte, da die actio Serviana deutlich zum Ausdruck bringt, dass aus dem (dinglichen) Pfandrecht jemand nicht haften können müsse, außer hinsichtlich der Sachen, die der Schuldner im Vermögen hatte, und es ist unverbrüchlich sicher, dass einer durch eine fremde Sache gegen den Willen des Eigentümers nicht verpflichtet werden könne.

Die gültige Schenkung ${ }^{85}$ der Frau an ihre Söhne erfolgt vor der Verpfändung, zu einem Zeitpunkt, da die Mutter also nicht mehr Eigentümerin war und auch sonst über die Liegenschaft nicht verfügen konnte. Daher haftet sie - entsprechend dem klassischen römischen Recht - aus dem iudicium contrarium $^{86}$.

In all den bisher genannten Belegen bezieht sich die actio pigneraticia in personam contraria jeweils auf den Ersatz des dem Pfandgläubiger entstandenen Schadens: 'Der Gläubiger sieht sich in seiner Annahme getäuscht, durch das Pfand bei eintretender Fälligkeit voll gedeckt zu sein'87: Sein Sicherungsinteresse, sein Vertrauen 'a ricevere una cosa che potesse assolvere la funzione di garanzia del proprio credito's8 ${ }^{88}$ ar verletzt ${ }^{89}$. Modern ließe sich dies als eine Leistungsstörung wie Rechtsmangel ${ }^{90}$ oder Schadenersatz ${ }^{91}$ qualifizieren $^{92}$.

85 Anders ist zB. die Schenkung eines Ehemanns an seine Frau kein Hindernis für eine nachträgliche Verpfändung, da der Mann mangels gültiger causa weiterhin Eigentümer der Liegenschaft ist. Die nachträgliche Verpfändung wird auch nach Ableben des Mannes als Widerruf der Schenkung interpretiert und fällt daher nicht unter den Anwendungsbereich der oratio Antonini, vgl. D. 24,1,32,5 (Ulp. 33 ad Sab.) und dazu Bürge, Retentio (supra, n. 26), S. 123 Anm. 65 mit Literatur.

86 Dass Diokletian hier die dem klassischen Recht entsprechende Lösung präferiert, ist nicht ungewöhnlich, vgl. so etwa zur Konvaleszenz des Pfandrechts C. 8,15,5 (Diocl.Max. Eutycho, a. 286), wo die actio utlis gewährt wird, wenn die verpfändete fremde Sache nachträglich in bonis des Pfandbestellers gelangt; zur Klassizität auch dieser Lösung vgl. A. Wacke, Die Konvaleszenz von Pfandrechten nach römischem Recht, zss romAbt 115 (1998), S. 438-461, 444 .

87 So Schwarz, Konträrklagen (supra, n. 15), S. 136 unter Verweisen auf just D. 13,7,9pr.

88 Sciandrello, Ricerche (supra, n. 75), S. 13o; ähnlich ebenda 137.

89 Schwarz, Konträrklagen (supra, n. 15), S. 138; vgl. dazu Glück, Ausführliche Erläuterung (supra, n. 33), S. 133 u. 156; A. Löffelmann, Pfandrecht und Sicherungsübereignung an künftigen Sachen, Köln-Weimar-Wien 1996, S. 144.

90 P. Apathy / G. Klingenberg / M. Pennitz, Einführung in das Römische Recht, Wien 52012, S. 141.

$91 \quad$ H. Honsell / Th. Mayer-Maly / W. Selb, Römisches Recht, Berlin e.a. ${ }^{41987}$, S. 203.

92 W. Ernst, Rechtsmängelhaftung, Tübingen 1995, S 18-19 spricht - allerdings in Zusammenhang mit der Eviktion der Pfandsache beim Käufer, der vom Gläubiger erworben 
In D. 46,1,54 (Paul 3 quaest.) sagt Paulus, freilich in einem anderen Kontext, explizit, dass die Konträrklage auf das quod interest creditoris abziele:

Si in pignore contrahendo deceptus sit creditor, qui fideiussorem pro mutuo accepit, agit contraria pigneraticia actione, in quam actionem veniet quod interest creditoris. sed ea actio fideiussorem onerare non poterit: non enim pro pignore, sed pro pecunia mutua fidem suam obligat.

Wenn ein Gläubiger, der einen Bürgen für (die Gewährung von einem) Darlehen annahm, bei Abschluss eines Pfandrealvertrags getäuscht worden ist, klagt er mit der Konträrklage aus dem Pfandrealvertrag, in welche einfließen wird, was das Interesse des Gläubigers ausmacht. Aber diese Klage kann den Bürgen nicht belasten: Nicht nämlich für den Pfandrealvertrag, sondern für das dargeliehene Geld hat er gebürgt.

Der Pfandbesteller hatte hier den Pfandgläubiger getäuscht, dieser klagt mit der actio contraria auf das Interesse: in quam actionem veniet quod interest creditoris'. Auch wenn der Fall mit dem verschuldensunabhängigen Einstehen für das rem alienam pignori dare nicht vergleichbar ist - hier liegt eine Täuschung vor, die auch nicht notwendiger Weise in der Vorspiegelung der Tatsache bestanden haben muss, dass die Sache in bonis debitoris sei - so besteht der Schaden des Gläubigers, dessen Anspruch noch nicht fällig ist ${ }^{93}$, wieder in der Gefährdung seines Sicherungsinteresses.

Die Konträrklage wird überall dort gewährt, wo dieses Interesse bei Abschluss des Pfandrealvertrages verletzt ist ${ }^{94}$, und das unabhängig vom Wissen des Pfandgebers ${ }^{95}$. Sie geht auf 'den Wert, den nach dem Verpfändungsvertrag die Sache als Pfand für den Gläubiger hat', den Verkaufserlös der Pfandsache bis zum Betrag der eigenen Forderung ${ }^{96}$. In keinem der genannten Fälle aber ist davon zu lesen, dass ein Ersatzpfand zu bestellen sei, wie schon Sintenis eindringlich festgehalten hat: 'Die Pfandgegenklage hat in diesen Fällen gleich der in factum bei bloßen Hypothekarverträgen das Interesse des Gläubigers

hat - davon, dass sich der Gläubiger mit der Konträrklage beim Schuldner schadlos halten konnte 'wegen des Haftungsschadens, den er aufgrund des Pfandverkaufs der fremden Sache erleidet'.

93 Stein, Fault (supra, n. 12), S. 133.

94 Vgl J.G. Wolf, D. 20.1.27 Marc. 5 dig, Zur Aktivlegitimation des Pfandgläubigers für die actio legis Aquiliae, zss romAbt 76 (1959), S. 520-534, 531-532.

95 Vgl. auch Sciandrello, Ricerche (supra, n. 75), S. 131 Anm. 144 unter Bezugnahme auf D. $13,7,9 \mathrm{pr}$.

96 Reichard, Frage des Drittschadensersatzes (supra, n. 56), S. 200; C.A. Cannata, Le disavventure del capitano J.P. Vos, Labeo 41 (1995), S. 387-432, 414-415; vgl. auch P. Frezza, Le garanzie delle obbligazioni, Corso di diritto romano, vol. 2: Garanzie reali, Padova 1963, S. 136. 
zum Gegenstande, nicht die Bestellung eines anderen Pfandes, wie sich häufig irrig gelehrt findet, obwohl der Pfandbesteller dadurch der erhobenen Klage ausweichen kann.'97 Auf Basis des Wortlauts von D. 13,7,16,1, D. 13,7,32, D. $13,7,36,1$ und eben D. 13,7,9pr. ${ }^{98}$ ist daher nicht nachvollziehbar, warum diese Texte regelmäßig als Belege dafür zitiert werden, dass der Gläubiger, dem eine res aliena als Pfand übergeben worden war, vom Pfandbesteller contrario iudicio eine andere, geeignete Pfandsache fordern dürfen soll.

\section{4 \\ Der Pfandrealvertrag und die actio pigneraticia in personam contraria}

Die Verurteilung auf das Interesse stellt allerdings die Verurteilung des Pfandgebers zur Erbringung einer Sekundärleistung dar, die aus Prozessnovation nach litis contestatio resultiert ${ }^{99}$. Nach Provera etwa haftete der Pfandbesteller nicht deshalb, weil er eine Vertragspflicht zur Bestellung eines geeigneten Pfandes verletzt habe, sondern bezog sich die Konträrklage auf 'un obbligo secondario ed eventuale di indennizzo'100. Dennoch ist im gegebenen Zusammenhang danach zu fragen, worin die Primärleistung des Pfandbestellers bestanden haben würde ${ }^{101}$.

97 Sintenis, Handbuch (supra, n. 45), S. 251. Sintenis verweist ebenda Anm. 3 auf D. 13,5,14,2 (Ulp. 27 ad ed.), D. 19,2,9pr. (Ulp. 32 ad ed.) und D. 46,1,54 (Paul. 3 quaest.).

98 Dies gilt auch für die korrespondierenden Basilikenstellen mit D. 13,7,16,1: Bas. 25.1.16 (= BT 1191,2-5), mit D. 13,7,32: Bas. 25.1.31 (= BT 1194,1-2), für. D. 13,7,36,1: Bas. 25,1,35,1 (= BT 1194, 17-19) und für D. 13,7,9pr: Bas. 25.1.ppr. (= BT 1189, 5-6).

99 Vgl. dazu nur Gai. 3.18o und dazu Kaser / Hackl, Zivilprozessrecht (supra, n. 53), S. 299-300. Sowohl nach sabinianischer als nach prokulianischer Ansicht zeitigt bei bonae fidei iudicia die Leistung nach litis contestatio absolutorische Wirkung; vgl. dazu auch D. Medicus, Zur Funktion der Leistungsunmöglichkeit im römischen Recht, zss romAbt 86 (1969), S. 67-104, 67-68; G. Albers, Perpetuatio obligationis, Leistungspflicht trotz Unmöglichkeit im klassischen römischen Recht, Wien-Köln-Weimar 2019, S. 143-144 und in Zusammenhang mit den Realverträgen F.B.J. Wubbe, I contratti reali alla fine della Repubblica, in: Contractus e pactum, Tipicità e libertà negoziale nell' esperienza tardo-repubblicana, Atti Copanello 1988, hrsg. von F. Milazzo, Napoli 1990, S. 109-121, 120-121 (= ders, Ius vigilantibus scriptum, Ausgewählte Schriften, hrsg. von P. Pichonnaz, Fribourg 2003, S. 313-327, 326327).

100 Provera, Una riforma (supra, n. 80), S. 352: 'Per diritto classico, (...), non ci si poneva dal punto di vista della responsibilità del pignorante per aver violato und obbligo contrattuale di dare in pegno un oggetto legittimamente pignorabile (...) bensì piu semplicemente si considerava il sorgere, in dipendenza delle singole situazioni di fatto, di un obbligo secondario ed eventuale di indennizzo che veniva appunto sanzionato con il iudicium contrarium'.

101 Vgl. so auch Kreller, Pfandedikt (supra, n. 15), S. 191 und in Zusammenhang mit der actio fiduciae W. Erbe, Die Fiduzia im römischen Recht, Weimar 1940, S. 157. 
Dazu ist es geboten, die prozessuale Perspektive einzunehmen, was bei Untersuchung der actio pigneraticia in personam contraria mit grundsätzlichen Problemen verbunden ist: Vielfach wurde ${ }^{102}$ vertreten, dass die Konträrklage erst von den Kompilatoren, anstelle der actio de dolo in den Text eingefügt worden sei ${ }^{103}$; auch wenn dem nicht zu folgen ist, so ist etabliert, dass die actio de dolo vor Einführung der Konträrklage deren Funktion wahrgenommen hat ${ }^{104}$ : Der Vorteil der vielleicht erst nach der julianischen Ediktsredaktion etablierten Konträrklage ${ }^{105}$ gegenüber der Arglistklage bestand darin, dass sie die dolose Begehung des Pfandgebers nicht voraussetzte ${ }^{106}$ und so jedenfalls zur Vergütung von Schaden- und Aufwandersatz gewährt werden konnte ${ }^{107}$ : Die actio pigneraticia in personam contraria ermöglichte also eine Erweiterung der reinen dolus-Haftung des Pfandbestellers im Sinne einer Garantiehaftung ${ }^{108}$.

102 d'Ors, Observaciones (supra n. 13-), S. 190-193; V. Arangio Ruiz, Instituzioni di Diritto romano, Napoli ${ }^{14} 1994$ (ND 2012), S. 315.

103 Vgl. dazu schon G. Beseler, Miscellanea critica, zss romAbt 43 (1922), S. 415-438, 429, der D. 13,7,9pr. allerdings als einen Fall des dolus in contrahendo versteht. Da er andererseits die zweite Variante 'aut malitiose in pignore versatus sit' tilgt, suggeriert er damit, dass der debitor dolos gehandelt hat, wovon im Text nichts zu lesen ist.

104 Kaser, Das Römische Privatrecht (supra, n. 27), S. 537; Arangio-Ruiz, Instituzioni (supra, n. 102), S. 315; F. Pastori, Il Commodato in diritto romano, Milano 1995, S. 446-447; Zimmermann, The Law of Obligations (supra, n. 52), S. 227-228; Kaser / Knütel / Lohsse, Römisches Privatrecht (supra, n. 64), S. 246. Die actio de dolo aber sah eine Verurteilung auf das quanti ea res erit vor - vgl. dazu nur Lenel, Edictum perpetuum (supra, n. 13), S. 115; Mantovani, Formule (supra, n. 20), S. 70 -, was zum gleichen Ergebnis führte wie dem, welches auch für die actio pigneraticia in personam contraria erarbeitet worden ist.

105 Lenel, Edictum perpetuum (supra, n. 13), S. 255-256; in diese Richtung wohl auch Kaser, Das Römische Privatrecht (supra, n. 27), S. 537 Anm. 16 und Kaser, Pfandrecht, II (supra, n. 1), S. 229: 'Das Aufkommen nach der julianischen Ediktsredaktion ist auch hier glaubhaft'; ebenso Kaser / Knütel / Lohsse, Römisches Privatrecht (supra, n. 64), S. 246; anderers spricht Wolf, D. 20.1.27 Marc. 5 dig. (supra, n. 94), S. 532, von der 'im Edikt längst etablierten actio pigneraticia contraria'.

106 Kaser, Das Römische Privatrecht (supra, n. 27), S. 537; Zimmermann, The Law of Obligations (supra, n. 52), S. 228.

107 Zum Aufwandersatz vgl. etwa D. 13,7,5 (Ulp. 31 ad ed.); D. 13,7,31 (Afr. 8 quaest.); allgemein vgl. Kaser, Pfandrecht II (supra, n. 1), p, S. 195-234; zustimmend Löffelmann, Pfandrecht (supra n. 89), S. 144-145.

108 Schwarz, Konträrklagen (supra, n. 15), S. 142-144; Kaser, Pfandrecht II (supra, n. 1), S. 224. Dies lässt sich auch aus dem bekannten Fall in D. 21,2,38 (Ulp. 2 disp.) ableiten, wonach der Pfandgläubiger dem Käufer der Sache nach deren Eviktion die Konträrklage abtreten soll; vgl. dazu Schwarz, Konträrklagen (supra, n. 15), S. 140-141; G. Wesener, Die Durchsetzung von Regressansprüchen im Römischen Recht, Labeo, 11 (1965), S. 341-351, 357; Kaser, Pfandrecht, II (supra, n. 1), S. 224-225; dazu, dass es sich bei dem Anspruch des Käufers gegen den Verpfänder um einen bereicherungsrechtlichen Anspruch handelt, da der pignoris nomine verkaufende Gläubiger unter Eviktionsausschluss kontrahiert hat, vgl. Reichard, Drittschadensersatz (supra, n. 56), S. 16o-206. Dazu ist auch auf D. 13,7,22,4 (Ulp. 30 ad ed.) zu verweisen, wonach der Pfandgläubiger, der nach Verkauf der res aliena und Eviktion 
Gerade aufgrund ihres über Fälle von dolus hinausgehenden Anwendungsbereichs ist gut argumentierbar, dass die Konträrklage in ius konzipiert gewesen sei $^{109}$ und eine bona fides-Klausel enthalten hat ${ }^{110}$.

Nach dem von Lenel entwickelten Schema ergibt sich der Wortlaut der Konträrklage aus einer 'Umstellung der Namen in der demonstratio der formula in

der Sache beim Käufer diesem das Interesse in der Höhe des dem Käufer stipulationsweise für den Eviktionsfall versprochenen Duplum ersetzt hat, die Konträrklage gegen den Pfandbesteller hat, wenn er ohne dolus oder culpa agierte.

109 Anders hat B. Biondi, Iudicia contraria, Annali del Seminario Giuridico di Palermo, 7 (1918), S. 59-175, vertreten, dass iudicium contrarium in factum konzipert gewesen sei; ebenso noch C. Rascon, Pignus y custodia en el derecho romano clasico, Oviedo 1976, S. 184-185; M. Talamanca, Elementi di diritto privato romano, Milano 2001, S. 283; Wegmann, Obligatio (supra, n. 68), S. 218 mit Anm. 249. Biondi, Iudicia, S. 94-95 verweist auf die Erteilung einer exceptio des Pfandbestellers gegen die Konträrklage des Pfandgläubigers in D. 13,7,3 (Ulp. $18 \mathrm{ad}$. Sab.), wobei strittig ist, welche Klage hier gemeint ist: Im bekannten Fall, dass der Pfandbesteller die Rückgabe des Pfandes erwirkt, sie einem Komplizen durchs Fenster zuwirft und damit den Realvertrag beendet, soll nach Labeo dem Pfandgläubiger die actio furti zugestanden werden. Wenn er aber mittels actio pigneraticia in personam contraria gegen den debitor vorgeht, so stehe ihm gegen dessen exceptio de pignore sibi reddito die replicatio de dolo et fraude offen. Daraus könnte man nun versucht sein, abzuleiten, dass die Konträrklage kein bonae fidei iudicium gewesen sein habe können - denn sonst hätte es ja keiner Einrede gegen sie bedurft. Doch diese Interpretation ist nicht zwingend richtig: Die den bonae fidei iudicia inhärenten Einreden waren die exceptio doli, quod metus causa und exceptio pacti, vgl. dazu Kaser / Knütel / Lohsse, Römisches Privatrecht (supra, n. 64), S. 204 (vgl. neuerdings aber Th. Finkenauer, Zur Inhärenz von Einreden im bonae fidei iudicium, erscheint in IVRA 68 [2020]). Kaser, Pfandrecht, II (supra, n. 1), S. 228 und G. Wesener, Nichtediktale Einreden, zss romAbt 112 (1995), S. 1o9150, 124, vermuten so auch, dass es sich bei der exceptio 'nicht um die den bonae fidei iudicia inhärente exceptio doli, sondern um eine eine exceptio in factum de pignore sibi reddito, die den Richter ausdrücklich auf den konkreten Sachverhalt hinweist', gehandelt habe. Zum Fall vgl. Sciandrello, Ricerche (supra, n. 75), S. 122-126, der das Wechselspiel von actio - exceptio - replicatio eher dem Pomponius als Labeo zuschreiben möchte; d'Ors, Observaciones (supra, n. 13), S. 191 hält den gesamten die actio contraria betreffenden Teil des Fragments für interpoliert. Ferner ist gar nicht gesichert, dass Pomponius hier die Konträrklage gemeint hat: Kreller, Pfandedikt (supra, n. 15), S. 182-183, erwägt stattdessen deliktischen und dinglichen Rechtsschutz für den Gläubiger: So hätten die Kompilatoren bei Integration des Fragments in den Titel de pigneraticia actione vel contra die Worte Serviana formula durch contraria pigneraticia ersetzt.

110 Gegen die Annahme nur einer in factum konzipierten Konträrklage allerdings Lenel, Edictum perpetuum (supra, n. 13), S. 255 und 256 mit Anm. 2. M. Kaser, Oportere und ius civile, zss romAbt 83 (1966), S. 1-46, 33, äußert sich dazu noch zweifelnd, vgl. aber Kaser, Pfandrecht, II (supra, n. 1), S. 92 Anm. 184; Kaser, Pfandrecht, II (supra, n. 1), S. 228, ebenso Mantovani, Formule (supra, n. 20), S. 53 Anm. 120; Finkenauer, Zur Inhärenz (supra, n. 109) bei Anm. 249. 
ius concepta' ${ }^{\prime 111}$ : contrarium bedeutet hier, dass die Klage im Verhältnis zur actio principalis in die entgegengesetzte Richtung geht ${ }^{112}$. Der Ausgangspunkt zur Rekonstruktion der actio pigneraticia in personam contraria ist daher - auch aufgrund der Unbestimmtheit der Leistungsinhalte ${ }^{113}$ - die in ius konzipierte Formel der actio directa ${ }^{114}$, deren Existenz ebenfalls umstritten ist ${ }^{115}$, mit Lenel $^{116}$ oder Kaser ${ }^{117}$ aber als gesichert angenommen werden kann ${ }^{118}$, zumal sie im Vergleich zur actio in factum für den Pfandgläubiger flexibler einsetzbar

111 Lenel, Edictum perpetuum (supra, n. 13), S. 253-254; ebenso schon A.F. Rudorff, De iuris dictione edictum, Edicti perpetui quae reliqua sunt, Leipzig 1869, S. 110; ferner Schwarz, Konträrklagen (supra, n. 15), S. 206-207; Mantovani, Formule (supra, n. 20), S. 52 Anm. 117; 53 Anm. 119 .

112 So Provera, Linee generali (supra, n. 41), S. 113-135, 121; Schwarz, Konträrklagen (supra, n. 15), S. 207.

113 So Kreller, Pfandedikt (supra, n. 15), S. 182: 'Versucht man aber die formula in factum concepta gegen den Verpfänder zu wenden, so muß man eine ganz neue intentio aufbauen'.

114 O. Lenel, Das Edictum perpetuum, Leipzig 1889, S. 202 und $^{2} 1907$, S. 247 argumentiert mit einer möglichen 'Zusammensetzung von actio directa / contraria in einer Formel ('quidquid alterum alteri dare facere oportet ex bona fide'). Diese Ansicht hat er in der 3 . Auflage von 1927, S. 254-256, nicht mehr vertreten.

115 Vgl. nur B. Biondi, L'elenco classico dei 'iudicia bonae fidei', Annali del Seminario Giuridico di Palermo, 7 (1918), S. 176-267, 233-241; d'Ors, Observaciones (supra, n. 13), S. 179-185; J. Paricio, Genesis e natura dei 'bonae fidei iudicia', in: Atti del Convengno 'Processo civile e Processo penale nell'esperienza giuridica del mondo antico', in memoria di Arnaldo Biscardi, Siena 2001, Milano 2011, S. 207-214, 209 mit Anm. 15.

116 Lenel, Edictum perpetuum (supra, n. 13), S. 255-256.

117 Kaser, Pfandrecht, II (supra, n. 1), S. 214-222; vgl. auch Sirks, Die Bedeutung (supra, n. 71), S. 84 Anm. 1.

118 Zum Forschungsstand auch Frezza, Le garanzie (supra, n. 96), S. 322-327; Rascon, Pignus y custodia (supra, n. 109), S. 178-189; W. Litewski, Das Bestehen der 'formula in ius concepta' mit der 'bona fides'-Klausel beim Pfand, Labeo 45 (1999), S. 183-192; J. de Churruca, Pignus, in: Derecho Romano de Obligaciones. Homenaje al profesor José Luis Murga Gener, hrsg. von J. Paricio, Madrid 1994, 333-386, 371-372; Mantovani, Formule (supra, n. 20), S. 53 Anm. 120. R. Knütel, Rez. M. Brauckmann, Pignus. Das Pfandrecht unter dem Einfluß der vorklassischen und klassischen Tradition der römischen Rechtswissenschaft, Göttingen 2008, in: IVRA 53 (2010), S. 303-319, S. 310 spricht davon, dass dies 'in der neueren Literatur überwiegend anerkannt ist'. Ein weiteres Argument liefert J. Alonso, Sull'accessorietà del pegno, in: Fides Humanitas Ius, Scritti in Onore di Luigi Labruna, I, hrsg. v. C. Cascione [/ C. Masi Doria, Napoli 2007, S. 77-99, 88 Anm. 27 hinsichtlich D. 13,7,11,2 (Ulp. 28 ad ed.): In diesem Fall, wo ein Pfand übergeben wurde, ohne dass eine Schuld bestand, bejaht Upian die actio pigneraticia auf Rückgabe; der Formelwortlaut der actio pigneraticia in factum jedoch erhebt alternativ solutio, satisfactio oder mora creditoris zur Kondemnationsbedingung, was hier nicht der Fall sein kann. Dies ist nach Alonso 'un indizio forte ... in favore della discussa formula in ius di buone fede'. 
schien $^{119}$. Die in ius konzipierte Klage, wohl ebenfalls jünger als die julianische Ediktsredaktion ${ }^{120}$, könnte also gelautet haben:

Quod Aulus Agerius Numerio Negidio rem qua de agitur ob pecuniam debitam pignori dedit, quidquid ob eam rem Numerium Negidium Aulo Agerio dare facere oportet ex fide bona, eius Numerium Negidium Aulo Agerio condemnato. Si non paret, absolvito.

Aus der genannten 'Umstellung' ergibt sich daher für die Konträrklage der folgende Wortlaut ${ }^{121}$ :

Quod Numerius Negidius Aulo Agerio rem qua de agitur ob pecuniam debitam pignori dedit, quidquid ob eam rem Numerium Negidium Aulo Agerio dare facere oportet ex fide bona, eius Numerium Negidium Aulo Agerio condemnato. Si non paret, absolvito.

Der Pfandbesteller kann darauf geklagt werden, was er aufgrund von Treu und Glauben zu tun oder leisten verpflichtet ist: quidquid dare facere oportet ex bona fide. Diese intentio incerta 'deutet bereits an, dass die Verurteilung nur auf

119 Noch unentschieden ist Kaser, Oportere (supra, n. 110), S. 32; vgl. aber Kaser, Pfandrecht, II (supra, n. 1), S. 222; denkbar wäre auch, dass die Herausforderung des superfluum oder eines mittels actio furti erstrittenen Überschusses - D. 47,2,15pr. (Paul. 5 ad Sab.) - mit der in ius konzipierten einfacher zu betreiben war als mit einer in factum konzipierten Klage, vgl. dazu Kaser, Pfandrecht, II (supra, n. 1), S. 216 Anm. 125.

Schwarz, Konträrklagen (supra, n. 15), S. 205-206; Kaser, Pfandrecht, II (supra, n. 1), S. 234; Mantovani, Formule (supra, n. 20), S. 53 Anm. 120; Kaser / Knütel / Lohsse, Römisches Privatrecht (supra, n. 64), S. 246. Kreller, Pfandedikt (supra, n. 15), S. 179-180, verweist demgegenüber auf die Erwähnung mehrerer actiones pigneraticiae durch Julian in D. 13,7,13pr. (Ulp. 28 ad ed.): Allerdings sind die Digesten Julians nach D. Liebs in: Handbuch der lateinischen Literatur der Antike, Band 4, hrsg. von R. Herzog / P.L. Schmidt, München 1997, S. 104 (§ 414) frühestens um 153 n. Chr. verfasst, als Julian kein Staatsamt mehr bekleidete, also 20 Jahre nach der Ediktsredaktion. Möglicherweise ist mit dem Plural actiones pigneraticiae die Pfand- und die Fiduzia-Klage gemeint, vgl. Kaser, Pfandrecht, II (supra, n. 1), S. 343; Knütel, Rez. M. Brauckmann (supra, n. 118), S. 310 Anm. 17. Th. Finkenauer, Drittwirkende pacta im klassischen Recht, zss romAbt 135 (2018), S. 17826o, 240 wendet demgegenüber ein, dass eine kompilatorische Zusammenfassung eher die actio fiduciae getilgt hätte als die actio pigneraticia in den Plural zu setzen. Wolf, D. 20.1.27 Marc. 5 dig. (supra, n. 94), S. 532, vermutet hingegen, dass die Klage 'längst anerkannt und im Edikt proponiert worden' war; ebenso Litewski, Das Bestehen (supra, n. 118), S. 192.

121 Kaser Pfandrecht II (supra, n. 1), S. 92; Mantovani, Formule (supra, n. 20), S. 53 Anm. 120, verzichtet auf eine Rekonstruktion. 
Geld lauten kann'122, da das 'Unbestimmtheitspronomen'123 quidquid mit dem eius der condemnatio korrespondiert. Doch das sagt noch nichts darüber aus, was das dare facere oportere des Schuldners ausmachte: Der Richter wird durch die Formel ja nur angewiesen, auf den Geldwert dessen zu verurteilen, was der Beklagte dem Kläger nach dessen Behauptung schuldet, wenn sich diese als richtig erweist ${ }^{124}$.

Die demonstratio der actio pigneraticia legte die Grenzen der richterlichen Prüfungspflicht und Prüfungsmöglichkeit im Verfahren apud iudicem fest: Diese durch Ausgliederung der Sachverhaltsdarstellung ${ }^{125}$ aus der intentio ${ }^{126}$ gewonnenen Parameter dienen der Identifikation des Streitgegenstandes ${ }^{127}$ und vor allem: der Interpretation des dare facere oportere ex fide bona ${ }^{128}$. Damit wird die auf der bona fides beruhende ${ }^{129}$ oder nach ihr bemessene ${ }^{130}$ Leistungspflicht zum einen von der Tatsache abgesteckt, dass der Beklagte dem Kläger eine Sache zum Pfand gegeben hatte: rem ... pignori dedit, und zum an-

122 Kaser / Knütel / Lohsse, Römisches Privatrecht (supra, n. 64), S. 461; vgl. dazu auch Zimmermann, The Law of Obligations (supra, n. 52), S. 771.

123 F. Wieacker, Zum Ursprung der bonae fidei iudicia, zss romAbt 8o (1963), S. 1-41, 34.

124 Vgl. M. Kaser, Formeln mit 'intentio incerta', 'actio ex stipulatu' und 'condictio', Labeo, 22 (1966), S. 7-29, 10.

125 Dies wird auch durch den Rückverweis (ob eam rem) von der intentio auf die demonstratio noch besonders akzentuiert, vgl. U. Babusiaux, Id quod actum est, Zur Ermittlung des Parteiwillens im klassischen römischen Zivilprozeß, München 2006, S. 168.

126 Vgl. Wieacker, Zum Ursprung (supra, n. 123), S. 34, der darauf verweist, dass erst dadurch der Richter einen größeren Urteilsspielraum erhalten hat; zustimmend W. Selb, Formeln mit unbestimmter intentio iuris, Studien zum Formelaufbau, Teil I, Wien-Köln-Graz 1975, S. 13-15; Kaser, Oportere (supra, n. 110), S. 26. Allerdings darf die Funktion der demonstratio gegenüber der intentio incerta nicht allein als in dieser Abgrenzung der Sachverhaltsdarstellung vom klägerlichen Begehren erschöpft angesehen werden, vgl. Babusiaux, Id quod actum est (supra, n. 125), S. 169 .

127 W. Selb, Die Formel der Injurienklage, in: Essays in honour of B. Beinart, hrsg. von W. De Vos e.a., Cape Town 1979 [= Acta Juridica (1978)], S. 29-38, 32.

128 Selb, Formeln (supra n. 126), S. 45; W. Selb, Zu den Anfängen des Formularverfahrens, in: Festschrift für Werner Flume zum 70. Geburtstag, hrsg. von H.H. Jacobs / B. Kobbe-Keuk / E. Picker / J. Wilhelm, Köln 1978, S. 199-204, 203; R. Cardilli, Damnatio e oportere nell'obbligazione, Napoli 2016, S. 244; zum Verhältnis von intentio incerta und demonstratio vgl. auch G. Sacconi, La pluris petitio nel processo formulare, Contributi allo studio dell'oggetto del processo, Milano 1977, S. 190-194.

129 Vgl. dazu nur W. Kunkel, Fides als schöpferisches Element im römischen Schuldrecht, in: Festschrift Paul Koschaker, II. Band, Weimar 1939, S. 1-15, 5.

130 So Wieacker, Zum Ursprung (supra, n. 123), S. 3, 18, 29, 33-37 und 40-41; A. Carcaterra, Intorno ai bonae fidei iudicia, Bari 1964, S. 36-79; hierin zustimmend F. Wieacker, Bonae fidei iudicia, Labeo, 12 (1966), S. 250-258, 253; ebenso Kaser, Oportere (supra, n. 110), S. 14; F. Wieacker, Römische Rechtsgeschichte, München 1988, S. 453-454 u. 458. 
deren davon, dass eine individuell bestimmte Sache Gegenstand des Realvertrages ist: rem, qua de agitur.

Mit rem pignori dare wird in der demonstratio der Abschluss des Pfandrealvertrages umschrieben: Im Unterschied zur intentio der in factum verfassten Formel mussten hier nicht alle Voraussetzungen der Verurteilung ${ }^{131}$ angeführt werden, da ja nur die vertragliche Verpfändung Grundlage der Haftung ist ${ }^{132}$. Aus den Worten pignori dare folgt, dass die Sache zum Pfand gegeben und angenommen worden ist ${ }^{133}$, damit werden also die körperliche Übergabe der Pfandsache (datio) und die Einigung über den Zweck derselben (conventio) angesprochen.

Die so paraphrasierte conventio selbst beinhaltet vordringlich die $\mathrm{Zu}$ stimmung zu Hingabe und Empfang der Sache zum Pfand ${ }^{134}$ und legt die Modalitäten der Pfandbestellung fest: Dies umfasste neben der zu sichernden Forderung und der Art der Pfandverwertung ${ }^{135}$ auch die Definition des Pfand-

131 Vgl. dazu oben unter 1, bei Anm. 131.

132 Vgl. Lenel, Edictum perpetuum (supra, n. 13), S. 254-255 gegen Rudorff, De iuris dictione edictum (supra, n. 111), S. 110-111: Nur die Verpfändung, nicht aber die Schuldtilgung und andere Voraussetzungen sind Grund der Haftung, des dare facere oportere; vgl. dazu auch Kaser, Pfandrecht, II (supra, n. 1), S. 221.

133 So Kaser, Pfandrecht, II (supra, n. 1), S. 198-199, in Bezug auf das Verheißungsedikt der actio pigneraticia in factum concepta gegen Kreller, Pfandedikt (supra, n. 15), S. 162, der auch noch die Ergänzung der Klausel 'si quid de ea re pactum conventumve esse dicetur' angeregt hat.

134 So auch Brauckmann, Pignus (supra, n. 19), S. 44 in Auslegung von D. 12,1,1,1 (Ulp. 26 ad ed.); hierin zustimmend Knütel, Rez. Brauckmann (supra, n.118), S. 309, der die festgelegten 'Zwecke' mit Zurückbehalten- und Verwertendürfen durch den Pfandgläubiger definiert. Der Zweck der Übergabe ergibt sich primär aus der actio pigneraticia in factum concepta: Sie ist auf Rückgewähr der vom Vertragspartner erhaltenen Sache gerichtet, wenn die Schuld getilgt worden ist und für den Gläubiger kein rechtfertigender Grund dafür besteht, die Sache zurückzuhalten (also: keine iusta causa retinendi); zum Retentionsrecht des Pfandgläubigers beim pignus vgl. etwa Bürge, Retentio (supra, n. 26), S. 172-175. Auch die actio pigneraticia in ius concepta zielt auf Rückgabe der pfandhalber übergebenen Sache, lässt aber aufgrund der intentio incerta breiteren Interpretationsspielraum, welche Verpflichtungen aus dem rem pignori dedisse entspringen können.

135 Andererseits liegt der Fokus beim Pfandrealvertrag auf der Abwicklung des Pfandverhältnisses nach Erlöschen der Schuld oder zweckgemäßem Einsatz der Pfandsache, vgl. dazu M. Kaser, Besitzpfand und besitzloses Pfand (Studien zum römischen Pfandrecht, III), Studia et Documenta Historiae Iuris, 45 (1979), S. 1-92, 34. 
gegenstandes ${ }^{136}$. Zur Auslegung des dare facere oportere ex fide bona ist es also notwendig, die jeweilige conventio zu kennen ${ }^{137}$ oder zu ermitteln: Die Leistungspflicht, das dare facere oportere ex fide bona aus dem Pfandrealvertrag, wird von der conventio bestimmt, und wie bei allen bonae fidei iudicia gilt: 'quod si nihil convenit, tunc ea praestabuntur, quae naturaliter insunt huius iudicii potestate' ${ }^{\prime 38}$. Allerdings ist für D. 13,7,9pr. nicht erhebbar, ob die conventio ausformuliert oder ein hypothetischer Parteiwillen erst zu erschließen ist. Deshalb sollen hier andere Beispiele bemüht werden.

Als typische conventio soll hier mit TPsulp 79 (15. März $40 \mathrm{n}$. Chr. $)^{139}$ ein Dokument aus dem Sulpizierarchiv zitiert werden, das freilich wohl noch lange vor die Einführung der actio pigneraticia contraria - und wohl auch jener der in ius konzipierten Pfandrealvertragsklage - datiert. Der Vertragstext enthält folgende Angaben:

\author{
C(aio) Laecanio Basso Q(uinto) Terentio Cull[eone] co(n)s(ulibus), \\ ìdibus Mar[tiis] \\ L(ucius) $\mathrm{Ma}$ [rius Didae l(ibertus) Iucundus scripsi me dedisse C(aio) \\ Sulpicio] \\ $\mathrm{Fa}$ [usto pignoris nomine triti]ci Alexander[drini modium] \\ 5 millia [decem et tri]a, quae sunt posita in [pr]aedis Do[miti] \\ ae Lepidae [h]orreis Barbatianis superioribus [horreo] \\ XXVI ob HS viginti millia nu[mmum, quae per chiro] \\ graphum scripsi me ei debere [---]. \\ Si idibus Maìs primis ea Hs ((I)) [(()I )), q(uae) s(upra) s(cripta) s(unt), \\ non de[dero] sol[vero] \\ 10 satisve fecero, tum liceat tibì id triticu[m, quo de agitur,] \\ sub [p]raecone de condicione pig[nor]is? quo [d(e) ag(itur) vendere]. \\ [Si pluris venier] it, tu omne quod superesse[t] reddas [mihi he]
}

136 Vgl. Kaser, Pfandrecht, II (supra, n. 1), S. 198 in Zusammenhang mit der vertraglichen Pfandrechts-conventio: 'Sie (= die Pfandabrede) war dazu bestimmt, die Sache der Pfandbindung zu unterwerfen und zugleich die vereinbarten Modalitäten der Pfandbestellung, also die zu sichernde Forderung, die Abgrenzung des Pfandgegenstands (etwa durch Einbeziehung der Früchte) und die Art der Pfandverwertung (Verfall, Verkauf usw. mit ihren Einzelheiten) festzulegen'.

137 Die Bedeutung der Vertragsauslegung zur Interpretation der Leistungspflichten hat Babusiaux, Id quod actum est (supra, n. 125), S. 169-170 für die actio empti herausgearbeitet, hier lassen sich durchaus Parallelen ziehen.

138 D. 19,1,11,1 (Ulp. 32 ad ed.); vgl. dazu Babusiaux, Id quod actum est (supra, n. 125), S. 219.

139 Vgl. G. Camodeca, Tabulae Pompeianae Sulpiciorum (TPsulp.), Edizione critica dell'archivio puteolano dei Sulpicii, Roma 1999, S. 181-183; H.G. Wolf, Neue Rechtsurkunden aus Pompeji, Darmstadt 2010, S. 104-105 (dort: TP 69). 
[redive meo; si] quo minoris venierit, id ego reddam tibì

heredive tuo. Utique id triticum, quo de agitur,

omni periculo esset meo heredisve meì: haec

mihì tecum ita convenerunt pactusque sum.

\section{Actum Puteolis.}

Unter den Konsuln Gaius Laecanius Bassus und Quintus Terentius Culleo | an den März-Iden. | Ich, Lucius Marius Iucundus, Freigelassener der Dida, habe geschrieben, daß ich gegeben habe Gaius Sulpicius | Faustus zum Pfande von Alexandrinischem Weizen modii | dreizehntausend, die eingelagert sind auf $\mid$ den oberen Barbatianischen Besitzungen der Domitia Lepida im Speicher $\mid 26$, wegen der Sesterzen zwanzigtausend, von denen ich in einem $\mid$ Chirographum geschrieben habe, $<$ daß ich sie Gaius Sulpicius Faustus schulde>. | Wenn ich an den nächsten Mai-Iden diese Sesterzen 20000 , die oben geschrieben sind, nicht werde gegeben, geleistet, | gezahlt haben, dann soll es Dir erlaubt sein, diesen Weizen, um den es geht, $\mid$ in einer Auktion zu verkaufen gemäß der Bestimmung ........ | Wenn er um mehr (als den Betrag der Forderung) verkauft wird, so wirst Du alles, was (nach Abzug des Schuldbetrags) übrig bleibt, mir | oder meinem Erben herausgeben; wenn er um weniger verkauft wird, (als ich schulde), so werde ich das zahlen Dir | oder deinem Erben (was fehlt). Auf jeden Fall soll dieser Weizen, um den es geht, | auf meine oder meines Erben uneingeschränkte Gefahr lagern. Dies | ist von mir mit Dir so vereinbart worden und habe ich ausbedungen. | Geschehen zu Puteoli. 140

Die conventio beschreibt nach Datierung die pfandweise Übergabe ${ }^{141}$ von 13000 Scheffel (modii) ${ }^{142}$ alexandrinischen Weizens ('scripsi me dedisse ... pig-

140 Übersetzung: Wolf, Neue Rechtsurkunden (supra n. 139), S. 105.

141 Als Besitzpfand qualifiziert es etwa P. Gröschler, Die Mittel der Kreditsicherung in den tabulae ceratae, in: Pistoi technèn, Bankers, Loans and Archives in the Ancient World, Studies in Honour of Raymond Bogaert, hrsg. von K. Verboeven / K. Vandorpe V. Chankowski, Leuven 2008, S. 301-319, 315. Gegen eine Übergabe argumentiert aber G. Krämer, Das besitzlose Pfandrecht, Köln-Weimar-Wien 2007, S. 334-338: So sei das Getreide beim Schuldner Iucundus verblieben und nicht übergeben worden. Die Anmietung des Speichers habe Faustus erst nach Fälligkeit der Schuld betrieben - die Datierung von TPSulp. 46 ist aufgrund der schwierigen Lesbarkeit des Textes nicht genau zu ermitteln, Krämer, S. 335 schlägt den 16. Mai vor; erst nach Fälligkeit des Darlehens am 15. Mai habe sich Faustus also in Besitz des Getreides gesetzt, um es zu verkaufen; vorsichtig zustimmend Knütel, Rez. M. Brauckmann (supra, n. 118), S. 319.

Das entspricht 87 Tonnen Weizen. 
noris nomine') und ihre bereits erfolgte Einlagerung in extra zu diesem Zweck angemieteten Speichern ${ }^{143}$. Ferner werden die Schuldsumme in der Höhe von 20000 Sesterzen und das dies belegende chirographum ${ }^{144}$ genannt, dem Gläubiger der Verkauf bei Fälligkeit und Nichtbegleichung der Schuld gestattet sowie die Szenarien eines Überschusses oder $\mathrm{zu}$ geringen Verkaufserlöses geregelt.

Das Pfandobjekt ist, wenn Camodecas Datierung von TPsulp 46 auf den 13 . März 40 v. Chr. stimmt ${ }^{145}$, nach der zwei Tage zuvor erfolgten Einlagerung in einem Speicher ${ }^{146}$ abgewogen und damit individualisiert worden ${ }^{147}$. Gleich zweimal wird es in der - wenn hier auch größtenteils ergänzten - conventio explizit genannt: id triticum quo de agitur heißt es einmal in Zusammenhang mit dem - ab dem 2. Jh. n. Chr. der conventio wohl inhärenten ${ }^{148}$, hier noch

143 TPSulp 46.

144 Erhalten ist dies in TPSulp 53 (13. März 40 v. Chr.), vgl. Camodeca, Tabulae (supra, n. 139), S. 141-143; É. Jakab, Horrea, suretés et commerce maritime dans les archives des Sulpicii, in: Inter cives necnon peregrinos, Essays in honour of Boudewijn Sirks, hrsg. von J. Hallebeek / M. Schermaier / R. Fiori / E. Metzger / J.-P. Coriat, Göttingen 2014, S. 330-349, 335-338.

145 Vgl. dazu F. Klinck, Verpfändung und Speichermiete in den Tabulae Pompeianae Sulpiciorum, in: Facetten des römischen Pfandrechts, hrsg. von J.D. Harke, Heidelberg 2015, S. 55-73, 61. J.G. Wolf, Der neue pompejanische Urkundenfund, zss romAbt 118 (2001), S. 73132, 115 kann die Lesung Camodecas nicht bestätigen, dezidiert dagegen argumentiert Krämer, Das besitzlose Pfandrecht (supra, n. 141), S. 330-331.

146 TPSulp 46; vgl. dazu Camodeca, Tabulae (supra, n. 139), S. 124-126. Die Einlagerung in den vom Gläubiger gemieteten Speicher ist als datio zu interpretieren, vgl. E. Chevreau, $L a$ pratique du gage dans les Tabulae Pompeianae Sulpiciorum, in: Festschrift für Rolf Knütel zum 70. Geburtstag, hrsg. von H. Altmeppen / I. Reichard / M.J. Schermaier, Heidelberg 2009, S. 183-196, 189.

147 Vgl. dazu TPSulp 46 (13. März 40 n. Chr.), Z. 8-11. Der Speicher wird dem Gläubiger Gaius Sulpicius Faustus vermietet, Publius Annius Seleucus, der Vermieter, verspricht, das Getreide zuzuwägen: 'quae dominus meus admetietur servis suis'. Ein Vorteil für den Gläubiger bestand in der custodia-Haftung des Vermieters, vgl. Klinck, Verpfändung und Speichermiete (supra, n.145), S. 73. Zur Frage eines vorrangigen, den Mietzins betreffenden Pfandrechts des Vermieters am eingelagerten Weizen des Schuldners (der hier gleichsam Drittpfandbesteller für den Mietzins des Gläubigers ist) vgl. Klinck, Verpfändung und Speichermiete, S. 65-71.

148 D. 13,7,4 (Ulp. 41 ad Sab.): 'Si convenit de distrahendo pignore sive ab initio sive postea, non tantum venditio valet, verum incipit emptor dominium rei habere. Sed etsi non convenit de distrahendo pignore, hoc tamen iure utimur, ut liceat distrahere, si modo non convenit, ne liceat. Ubi vero convenit, ne distraheretur, creditor, si distraxerit, furti obligatur, nisi ei ter fuerit denuntiatum ut solvat et cessavit - Wenn eine Vereinbarung getroffen worden ist über den Verkauf des Pfandes, sei es von Beginn an, sei es später, dann ist nicht nur der Verkauf gültig, sondern dann hat der Käufer Eigentum an der Sache von Beginn an. Wenn aber keine Vereinbarung über den Pfandverkauf getroffen wurde, dann handeln wir dennoch nach dieser Rechtslage, dass es erlaubt sei, zu verkaufen, außer es ist vereinbart, dass es nicht erlaubt sei. Wo aber vereinbart ist, dass nicht verkauft werden dürfe, wird der Gläubiger, wenn er verkauft hat, aus Diebstahl haftbar, wenn er es 
ausdrücklich vereinbarten ${ }^{149}$ - pactum de vendendo ${ }^{150}$ bei Fälligkeit und Nichtzahlung151: tum liceat tibi id triticum quo de agitur / sub praecone de condicione .... vendere. Ein weiteres Mal spricht der Text in Zusammenhang mit der Gefahrtragungs-Klausel des Schuldners ${ }^{152}$ vom triticum quo de agitur. Das Pfandobjekt ist in der conventio pignoris genau definiert.

Auch in Fragmenten aus dem Titel D. 13,7 lassen sich Ansätze für die dem Vertrag jeweils zugrundeliegende conventio erkennen. In D. 13,7,36pr. (Ulp. 11 ad ed.) schiebt ein Pfandbesteller (aliquis) dem Gläubiger entgegen der conventio Erz statt Gold unter:

Si quis in pignore pro auro aes subiecisset creditori, qualiter teneatur, quaesitum est. in qua specie rectissime Sabinus scribit, si quidem dato auro aes subiecisset, furti teneri: quod si in dando aes subiecisset, turpiter fecisse, non furem esse. sed et hic puto pigneraticium iudicium locum habere, et ita Pomponius scribit. sed et extra ordinem stellionatus nomine plectetur, ut est saepissime rescriptum.

dem Schuldner nicht dreimal angezeigt hat, damit er leiste, und dieser es unterlassen hat'.

D. 13,7,5 (Pomp. 19 ad Sab.): 'Idque iuris est, sive omnino fuerint pacti, ne veneat, sive in summa aut condicione aut loco contra pactionem factum sit - Und dies ist rechtens, sei es, dass überhaupt vereinbart wurde, dass nicht verkauft werden dürfe, sei es, dass der Verkauf was den Kaufpreis, eine Bedingung oder den Ort betrifft, entgegen der Abrede geschehen ist'.

D. 20,5,9,1 (Paul. 3 quaest.): 'Pomponius autem lectionum libro secundo ita scripsit: quod in pignoribus dandis adici solet, ut, quo minus pignus venisset, reliquum debitor redderet, supervacuum est, quia ipso iure ita se res habet etiam non adiecto eo - Pomponius aber schrieb im 2. Buch seiner Lesungen folgendermaßen: Was bei den Bestellungen von Pfändern hinzugefügt zu werden üblich ist, dass, wenn er das Pfand um weniger (als die Schuld) verkauft hat, der Schuldner den Rest zahlen muss, ist vollkommen überflüssig, weil sich die Sachlage nach demselben Recht so verhält, selbst wenn dies nicht hinzugefügt worden ist'.

149 Vgl. dazu Gröschler, Die Mittel (supra, n. 141), S. 315-316.

150 Wie Krämer, Das besitzlose Pfandrecht (supra, n. 141), S. 324 Anm. 4 und 329, hervorhebt, ist das pactum de vendendo in den Zeilen 9-16 persönlich gehalten, anders als im vorangehenden Text der Urkunde ist von Ego und Tu zu lesen statt von Iucundus und Faustus. Krämer, S. 329, erklärt dies aus einer 'Mischung aus unterschiedlichen Formularen', oder daraus, dass 'die Verkaufsabrede als individuelle Zusatzvereinbarung (direkte Anrede in der zweiten Person) dem Standardformular beigefügt wurde'. Das pactum nimmt mit der Erwähnung von datio, solutio und satisfactio direkt Bezug auf die intentio der actio Serviana, vgl. dazu Chevreau, La pratique (supra, n. 146), S. 187.

$151 \quad$ TPSulp 79, Z.10-11.

152 TPSulp 79, Z. 14-15. 
Wenn irgendjemand bei Bestellung eines Pfandes für Gold Erz untergeschoben hat, wurde gefragt, wie er haften solle. In diesem Fall schreibt Sabinus äußerst richtig, dass er aus Diebstahl hafte, wenn er nach Übergabe von Gold Erz untergeschoben hat. In dem Fall aber, wenn er bei Übergabe Erz untergeschoben hat, hätte er schändlich gehandelt, sei jedoch kein Dieb. Hier nun glaube ich, dass die Klage aus dem Pfandrealvetrag am Platz sei, und ebenso schreibt es Pomponius. Sehr oft ist aber auch entschieden worden, dass er im Wege der außerordentlichen Gerichtsbarkeit wegen Stellionat bestraft wird.

Hier ist die zweite Fallvariante bedeutsam: Obwohl debitor und creditor sich darüber geeinigt haben, dass eine konkrete Sache aus Gold (aurum) zum Pfand dienen soll, übergibt der Pfandgeber eine Sache aus Erz (aes): 'in dando aes subiecisset'. Trotz einer 'schändlichen Handlung' (turpiter facere) des Pfandgebers kommt der Vertrag zustande und für den Pfandgläubiger gilt: 'sed et hic pigneraticium iudicium locum habere'. Dies erfolgt in Abgrenzung zur ersten Fallkonstellation, wo ein nachträglicher Austausch der Pfandobjekte den Pfandgläubiger zur actio furti gegen den Pfandgeber legitimiert: Sabinus stellt nur fest, dass dies in Variante 2 nicht möglich sei (non furem esse). Die jüngeren Juristen Ulpian und - vor ihm - Pomponius ergänzen das iudicium contrarium als Rechtsmittel des Pfandgläubigers ${ }^{153}$. Die conventio bezog sich auf eine Sache aus Gold, die zum Pfand gegeben werden sollte ${ }^{154}$.

Nicht anders entscheidet Ulpian in D. 13,7,1,2 (Ulp. 40 ad Sab.), wenn vom Pfandgeber - möglicherweise unbewusst ${ }^{155}$ - Erz anstelle von Gold übergeben wurde:

Si quis tamen, cum aes pignori daret, adfirmavit hoc aurum esse et ita pignori dederit, videndum erit, an aes pignori obligaverit et numquid, quia in corpus consensum est, pignori esse videatur: quod magis est. tenebitur tamen pigneraticia contraria actione qui dedit, praeter stellionatum quem fecit.

Wenn irgendwer, als er Erz zum Pfand gegeben hat, bekräftigte, dass dies Gold sei, und so die Pfandsache übergab, dann muss man sehen, ob

\footnotetext{
153 Sabinus könnte nach Schwarz, Konträrklagen (supra, n. 15), S. 136, 'die Konträrklage in der Funktion einer selbständigen Schadenersatzklage noch nicht gekannt haben'; ebenso Stein, Fault (supra, n. 12), S. 137-138.

154 Vgl. dazu auch Mentxaka, Stellionatus (supra, n. 76), S. 288-295.

155 F. Haymann, Die Haftung des Verkäufers für die Beschaffenheit der Kaufsache, Berlin 1912, S. 120; Provera, Linee generali (supra, n. 41), S. 347-348; Schwarz, Konträrklagen (supra, n. 15), S. 135; Stein, Fault (supra, n. 12), S. 136-137.
} 
etwa das Erz vom Pfandrealvertrag umfasst ist und ob nicht, da ja hinsichtlich des Gegenstandes eine Übereinstimmung erzielt wurde, er zum Pfand geworden zu sein scheint: Dies ist eher der Fall. Der, welcher gegeben hat, wird dennoch mit der Konträrklage aus dem Pfandrealvertrag haften - außer dem Tatbestand des Stellionats, den er begangen hat.

Trotz des error in materia ist nach Ulpian der Pfandrealvertrag über das (billigere) Metall zustande gekommen und die Konträrklage wird gewährt: tenebitur tamen pigneraticia contraria actione ${ }^{156}$. Die Irrtumsproblematik ist hier nicht weiter zu vertiefen ${ }^{157}$. Im gegebenen Zusammenhang ist vielmehr von Belang, dass beide Texte ${ }^{158}$ ausweisen, dass die conventio eine Definition des Gegenstandes enthielt, der zum Pfand gegeben wurde, und sich die Vereinbarung auf den hingegebenen Pfandgegenstand bezog ${ }^{159}$ : Die conventio etwa in D. 13,7,2,1 lautet darauf, dass (1) eine Sache zum Pfand gegeben wird (pignori daret) und (2) diese aus Gold sei (adfirmavit hoc aurum esse). Zu diesen

156 Die Begründung 'praeter stellionatum quem fecit' ist problematisch, vgl. Schwarz, Konträrklagen (supra, n. 15), S. 135-136: Der Verweis auf den Stellionat würde auch in D. 13,7,1,2 eine vorsätzliche Unterschiebung des billigeren Metalls voraussetzen, weswegen Haymann, Die Haftung (supra, n. 155), S. 120, den gesamten letzten Satzteil 'tenebitur-fecit' als 'angeflickt' verstanden hat. d'Ors, Observaciones (supra, n. 13), S. 191 vermutet wieder, dass ursprünglich von der actio de dolo zu lesen war. Anders argumentiert Mentxaka, Stellionatus (supra, n. 76), S. 282-283 dafür, dass der Begriff des Stellionats hier die Anwendbarkeit der actio pigneraticia contraria definiert.

157 H. Schwarz, Die Bedeutung des Geschäftswillens im römischen Kontraktsrecht der klassischen Zeit, Studia et Documenta Historiae et Iuris, 25 (1959), S. 1-54, 31 argumentiert mit der Sicherung des Pfandgläubigers, 'eher einen Gegenstand von schlechterer Substanz, als gar keinen Gegenstand zum Pfande zu haben'. M.J. Schermaier, Materia, Beiträge zur Frage der Naturphilosophie im klassischen römischen Recht, Wien-Köln-Weimar 1992, S. 148-149, erklärt sich das Zustandekommen des Vertrages daraus, dass damit zumindest einem 'gewissen Sicherungszweck' genüge getan wird, weshalb hier das pignus aufrechterhalten werden solle. W. Ernst, Irrtum, Ein Streifzug durch die Dogmengeschichte, in: Störungen der Willensbildung beim Vertragsschluss, hrsg. von R. Zimmermann, Tübingen 2007, S. 1-34, 13, erklärt die unterschiedliche Beachtung von error in materia bei Kauf und Pfandrealvertarg aus dem 'aktsbezogenen Ansatz' der römischen Juristen. D. Schanbacher, Ulpians Lehre vom error in substantia und die stoische Ontologie, in: Römische Jurisprudenz, Dogmatik, Überlieferung, Rezeption, Festschrift für Detlef Liebs zum 75. Geburtstag, hrsg. von K. Muscheler, Berlin 2011, S. 521 - 541, 541, erklärt die im Vergleich zum Kaufvertrag unterschiedliche Behandlung des error in substantia beim Pfandrealvertrag - so hätte Ulpian den Kauf bei beiderseitigem Irrtum für nichtig erklärt (S. 527-531) - damit, dass das pignus jünger ist als der Konsensualvertrag emptio venditio. Nur diesen hätte Ulpian auf Grundlage eines vorklassischen, wirklichkeitsabhängigen Konsens-Begriffs beurteilt.

$15^{8}$ Vgl. dazu auch Frezza, Le garanzie (supra, n. 96), S. 244-245; Sciandrello, Ricerche (supra, n. 75), S. 126-127.

So Schwarz, Die Bedeutung (supra, n. 157), S. 31 . 
Bedingungen (ita) werden eine conventio geschlossen und eine datio vollzogen (pignori dederit).

Somit wäre für D. 13,7,9pr. einzig zu überlegen, ob die Klage des Pfandgläubigers, da nur sekundär auf Interesseersatz gerichtet, auf ein Verhalten des Pfandbestellers in Bezug auf die res aliena pignori data rekurrieren kann: Nur sie ist Gegenstand des Vertrages, nur sie ist von der conventio umfasst, welche ja zur Auslegung des dare facere oportere ex fide bona heranzuziehen ist.

Dem in die demonstratio eingefügten, die Pfandsache (res) erläuternden Relativsatz qua de agitur ${ }^{160}$ kommt eine individualisierende Funktion hinsichtlich des Streitgegenstandes $\mathrm{zu}^{161}$. Die gesamte Phrase rem qua de agitur lässt sich als Blankett für die konkrete Sache verstehen, wie es andere Formeln durch Nennen eines 'Mustergegenstandes' wie der mensa argentea bei der $a c$ tio depositi ausdrücken ${ }^{162}$. Aus diesem in der demonstratio geschilderten 'Sachverhalt' nun resultiert eine Leistungspflicht des beklagten Pfandbestellers ${ }^{163}$.

Die unbestimmte intentio lautet auf das quidquid ... dare facere oportet ex fide bona. Die Leistungspflicht des Pfandgebers bezieht sich aufgrund der demonstratio, welche auf die conventio (und datio) einer bestimmten Sache verweist, auf eben diese res pignori data - nur sie wurde hingegeben.

Dies unterscheidet den Realvertrag pignus von einem Konsensualvertrag wie etwa der locatio conductio: Eine demonstratio wie 'quod Aulus Agerius

160 Davon zu unterscheiden ist das in vielen anderen Formeln der demonstratio nachgeschaltete qua de re agitur, das sich ganz allgemein auf 'die Angelegenheit, wegen der hier geklagt wird' bezieht, vgl. dazu die Übersetzung bei Kaser / Knütel / Lohsse, Römisches Privatrecht (supra, n. 64), S. 461 und 462 mit: 'in dieser Sache, deretwegen hier geklagt wird'. Damit wird Bezug genommen 'aufgrund welchen Lebenssachverhalts die Parteien den Prozess vor dem Prätor begründet haben' (S. 461); vgl. auch Babusiaux, Id quod actum est (supra, n. 125), S. 168-169.

161 Vgl. so die Begründung von H. Krüger, Die Worte 'qua de re agitur' und (res) 'qua de agitur' in den Prozeß 3 formeln, zss romAbt 25 (1908), S. 378-389, 388: 'Denn die Identität der eingeklagten körperlichen Sache mußte für den gegenwärtigen Prozeß wie für etwaige spätere Prozesse, in die die Frage der Klagenkonsumption hineinspielen konnte, restlos festgestellt, die Sache selbst so genau beschrieben werden, daß eine Verwechslung mit anderen Sachen derselben Gattung ausgeschlossen war'.

162 Kaser, Pfandrecht, II (supra, n. 1), S. 199 Anm. 21; 221 Anm. 153. Kreller, Pfandedikt (supra, n. 15), S. 169, ergänzt in der Musterformel der actio pigeraticia in factum concepta ebenfalls 'si paret ... mensam argenteam pignori dedisse'.

163 Kaser, Pfandrecht, II (supra, n. 1), S. 199 Anm. 21 betont, dass die genaue Bezeichnung der Sache nur dann notwendig gewesen sei, wenn Identifizierungszweifel drohten. 
Numerio Negido fundum quo de agitur conduxit' nennt dort zwar auch das Objekt eines Vertrages, etwa wie in der Rekonstruktion Lenels ${ }^{164}$ einen fundus quo de agitur. Die Liegenschaft muss hier allerdings noch nicht übergeben worden sein, vielmehr zeitigt ihre Miete / Pacht die Pflicht des Bestandgebers, die Liegenschaft dem Bestandnehmer zur Nutzung zu überlassen, und für den Fall, dass dies unterblieben ist, kann der locator mit der actio conducti auf Herausgabe geklagt werden ${ }^{165}$. Der Vertrag locatio conductio ist eben nicht aufgrund der Sachübergabe entstanden, sondern wegen des über die wesentlichen Vertragsinhalte erzielten Konsenses der Parteien. Der Konsensualvertrag weist in die Zukunft, schafft den Verpflichtungsgrund, um eine Verfügung durchzusetzen.

Demgegenüber ist der Realvertrag von Seiten des Schuldners / Pfandgebers mit seiner Begründung bereits erfüllt worden - er entstammt gleichsam einer 'Rechtskultur, die Verpflichtung und Erfüllung nicht trennen kann'166. Primäres Ziel des Pfandrealvertrages - auch als bonae fidei iudicium ${ }^{167}$ - war die Rückgewähr des Pfandes durch den Pfandnehmer: 'qui et ipse de ea ipsa re quam accepit restituenda tenetur' 168 . Wenn nun trotz erfolgter datio einer Sa-

164 Vgl. Lenel, Edictum perpetuum (supra, n. 13), S. 3oo; ebenso Mantovani, Formule (supra, n. 20), S. 54 .

165 Daneben diente die actio conducti für Schadenersatz- und Gewährleistungsansprüche des Bestandnehmers.

166 Fögen, Vom Typenzwang (supra, n. 68), S. 252.

167 Vgl. J.D. Harke, Studien zu Vertrag und Eigentumserwerb im römischen Recht, Berlin 2013, S. $30-31$.

168 D. 44,7,1,6 (Gai. 2 aur.). Gaius betont die Pflicht zur Rückgabe 'der Sache selbst' fast wortgleich auch in Zusammenhang mit dem commodatum in D. 44,7,1,3 (Gai. 2 aur.): 'sed is de ea ipsa re quam acceperit restituenda tenetur'. Diese Akzentuierung bezieht sich wohl auf die Speziesschuld aus dem Leihvertrag im Unterschied zur generischen Rückgabepflicht beim unmittelbar zuvor in D. 44,7,1,2 behandelten mutuum. Diesen Gegensatz leitetGaius mitsed ein, nachdem er dieGemeinsamkeiten zwischen Gebrauchsüberlassung von Darlehen und Leihe mit dem quoque betont hat, also: 'is quoque, cui rem aliquam commodamus, re nobis obligatur, sed is de ipsa re quam acceperit restituenda tenetur'. Auffällig ist, dass beim depositum in D. 44,7,1,5 (Gai. 2 aur.) auf das Pronomen ipsa verzichtet wird, wenn es heißt: 'qui et ipse de ea re quam acceperit restituenda tenetur', wogegen Gaius - wie oben ausgeführt - beim pignus wieder darauf rekurriert. Ebenso differenzieren die Institutionen Justinians IJ 3,14,2-4: Während in $§ 2$ beim commodatum ('et ob id de re ipsa restituenda tenetur') und $\S 4$ beim pignus ('qui et ipse de ipsa re') von der Rückgabe der Sache selbst zu lesen ist, verzichtet der Text beim depositum auf das Demonstrativpronomen ipsa ('qui et ipse de ea re quam accepit'). Ergänzend sei angemerkt, dass umgekehrt in dem mit D. 44,7,1.2-6 korrespondierenden Basilikentext nur beim Verwahrungsvertrag von der Rückgabepflicht 'der Sache selbst' zu lesen ist, vgl. Bas. 52.1.5

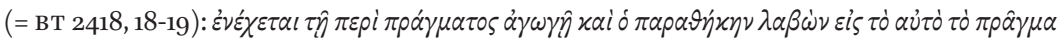
$\dot{\alpha} \pi \circ \propto \alpha \tau \alpha \sigma \tau \hat{\eta} \sigma \alpha \iota$ - Es haftet mit der Klage wegen der Sache auch der, welcher eine hinterlegte Sache übernahm, auf das Zurückstellen der Sache selbst'. 
che, trotz der diese determinierenden conventio weitere Pflichten des Pfandgebers bejaht wurden, die mit der Konträrklage durchgesetzt werden sollten, so mussten sie mit der übergebenen Sache selbst in Zusammenhang stehen, nicht aber auf ein zukünftiges Verhalten hinsichtlich einer anderen Sache gerichtet sein. Die Grenzen zwischen dem Realvertrag und dem Konsensualvertrag im Sinne einer vertraglich begründeten 'Pfandbestellungspflicht' des Schuldners könnten dann erst im justinianischen Recht verwischt worden $\operatorname{sein}^{169}$.

Von einer Entscheidung dieser Art kann für das klassische römische Recht keine Rede sein: Hier lag kein Pfandbestellungsvertrag, sondern ein Pfandrealvertrag vor, welcher auf Übergabe einer bestimmten Sache beruhte. Aufgrund des bereits gültig über die res aliena zustandegekommenen Pfandrealvertrags ist anzunehmen, dass der Pfandbesteller den Ersatz des Interesses schuldet.

Will man eine, aufgrund des Vertrages vom Pfandbesteller noch zu erbringen geschuldete Leistung konstruieren, so müsste diese in Zusammenhang mit der res data zu setzen sein: Sein oportere könnte so maximal darin bestehen, dass er einen Ausgleich dafür schafft, dass die Sache selbst, über die kontrahiert worden ist, die Eignung als Pfand erlangt: Da diese ja an der mangelnden dinglichen Berechtigung des Pfandbestellers gescheitert ist, könnte dies jedenfalls dadurch bewirkt werden, dass der Schuldner das Eigentum an der res aliena selbst erwürbe, an jener Sache, die er hingegeben hat und auf die sich die conventio mit dem Gläubiger bezog ${ }^{170}$. Mit dem Erwerb dieser Sache würde er dem Pfandgläubiger nachträglich dingliche Sicherung verschaffen, da das Pfandrecht konvaleszierte. Der Pfandgläubiger hätte dann wie im eingangs referierten Fall D. 13,7,41 (Paul. 3 quaest.) eine actio (pigneraticia in rem) utilis ${ }^{171}$.

169 Vgl. dazu oben 2 bei Anm. 40.

170 So ließe sich auch die bei Benke / Meissel, Übungsbuch (supra, n. 31), S. 198 - ebenso auch in den Auflagen Wien ${ }^{72001}$, S. 168, ${ }^{8} 2004$, S. $177,{ }^{9} 2008$, S. 197 und ${ }^{10}{ }_{2012}, 198$ - vertretene Meinung verstehen, wonach der Pfandgläubiger nach datio einer res aliena fordern könne, 'dass er ihm an einer Sache ein gültiges Pfandrecht einräumt'. Diese eine Sache könnte auch die Sache sein, die nachträglich ins Eigentum des Pfandbestellers gelangt ist. Nicht dem deutschen Wortlaut entspricht hier die englische Übersetzung des Übungsbuchs Sachenrecht, N. Benke / F.St. Meissel, Roman law of property, Origins and basic concepts of Civil law, I, translated by C.M. Grasl, Wien 2019, S. 196, wenn dort übersetzt wird: '... based on this contract, the pledgee may demand from the pledger the establishment of a valid right of pledge to the pledged property'. Das deckt sich zwar nicht zur Gänze mit dem deutschen Text, der von 'einer Sache' spricht; die insofern ungetreue Übersetzung weist aber in die hier vertretene Richtung.

171 Einen ähnlichen Fall beschreibt Papinian in D. 20,1,1pr. (Pap. 11. resp.): 'Conventio generalis in pignore dando bonorum vel postea quaesitorum recepta est: in speciem autem alienae rei collata conventione, si non fuit ei qui pignus dabat debita, postea debitori dominio quaesito difficilius creditori, qui non ignoravit alienum, utilis actio dabitur, sed facilior 


\section{Diese Interpretation des dare facere oportere ex fide bona ist zwar ebensowenig belegt ${ }^{172}$ wie jene, dass ein Ersatzpfand geschuldet wird. Auch ließe sich gegen}

erit possidenti retentio - Eine auf Pfandbestellung gerichtete, allgemeine Übereinkunft umfaßt von den Gegenständen [zwar] anerkanntermaßen auch später erworbene. Bei speziell auf eine fremde Sache gerichtete Verpfändung wird jedoch, wenn sie dem Pfandgeber nicht einmal geschuldet war, nachdem der Schuldner sie zu Eigentum erwarb, schwerlich dem Gläubiger, dem die Fremdheit nicht unbekannt war, eine analoge Pfandklage zu gewähren sein; eher darf er sie als Besitzer zurückhalten' - Übersetzung Wacke, Die Konvaleszenz (supra, n. 86), S. 451. Obwohl der debitor eine fremde Sache zum Pfand bestellt hatte, wird dem Pfandgläubiger bei nachträglichem Eigentumserwerb des Pfandbestellers eine actio utilis gewährt, wenn er im Verpfändungszeitpunkt (a) annahm, dass die Sache dem Pfandbesteller gehöre, oder (b) selbst, wenn er wusste, dass es eine res aliena ist, diese aber dem Pfandbesteller bereits geschuldet war und der Pfandbesteller einen Anspruch auf ihre Übereignung hatte: Diesbezüglich befand sich die verpfändete Sache zwar im Zeitpunkt der Verpfändung noch nicht in bonis, aber 'im Vorfeld des in bonis esse: der Rechtsboden für ihren Erwerb ist schon gelegt', vgl. Wacke, S. 451. Allerdings behandelt Papinian hier die 'Klagebegründungseignung von Pfandkonventionen': Die sachenrechtliche conventio ist mit dem Erwerb der fremden Sache bedingt. Die conventio bezieht sich allerdings auf das dingliche Pfandrecht, weswegen auch nicht von einer Übergabe der fremden Sache gesprochen wird wie in D. 13,7,9pr. Wie dort kommt im Zeitpunkt der Pfandbestellung noch kein dingliches Pfandrecht zustande: In beiden Fällen liegt jeweils eine res aliena vor, anders als in D. 13,7,9pr. war sie aber dem Pfandbesteller bereits geschuldet. Das kann für D. 13,7,9pr. nicht behauptet werden.

172 Die Quellen zur Konvaleszenz von Pfandrechten geben - abgesehen von den Fällen, wo dies im Erbgang erfolgt - kaum Hinweise darauf, wie der Pfandbesteller jeweils Eigentum an der vormals fremden Sache erlangt hat: Vielmehr wird allgemein formuliert, dass Eigentum erworben wurde, vgl. D. 13,7,41 (Paul. 3 quaest.): 'deinde dominus rei eius esse coepisti'; D. 20,1,1pr. (Pap. 11 quaest.): 'postea debitori dominio quaesito'; D. 20,4,9,3 (Afr. 8 quaest.): 'deinde domina eius pignoris facta'; C. 8,15,5 (Diocl./Max, a. 286): 'postea in bonis eius esse incipiat'. D. 20,4,3,1 (Pap 11 resp.) behandelt den nachträglichen Erwerb der zum Zeitpunkt der (ersten) Verpfändung bloß ex causa mandati geschuldeten Liegenschaft. Den nachträglichen Erwerb der verpfändeten, fremden Sache durch Kauf beim Eigentümer oder Zahlung der geschätzten Urteilssumme an diesen hat Wubbe, Res aliena (supra, n. 26), S. 93-94 und 277 in D. 20,1,21,1 (Ulp 73 ad ed.) hineinlesen wollen. Der Text lautet: 'Si debitor servum, quem a non domino bona fide emerat et pigneravit, teneat, Servianae locus est et, si adversus eum agat creditor, doli replicatione exceptionem elidet: et ita Iulianus ait, et habet rationem' - Wenn der Schuldner einen Sklaven, den er vom Nichteigentümer gutgläubig gekauft hatte und verpfändet hat, innehat, dann ist die actio Serviana am Platz, und, wenn gegen ihn der Gläubiger klagt, dann entkräftet er mit der Gegeneinrede der Arglist die Einrede: Und auch Julian sagt dies, und er hat Recht'.

Wubbe ergänzt nun vor teneat die Worte 'a domino redemptum' und bezieht dies auf den zweiten Erwerbstitel des Schuldners, nun vom Eigentümer. Wieacker, Zur Verpfändung (supra, n. 26), S. 69, möchte der Stelle nicht mehr entnehmen als dass 'sich der Verpfänder selbst gegenüber der Serviana des Pfandgläubigers nicht auf das Fehlen seiner Verfügungsbefugnis (...) berufen konnte. Wubbes mit vier Personen arbeitende Interpretation von D. 20,1,21,1 - dazu ausführlich Schanbacher, Konvaleszenz (supra, n. 1, S. 186-189 - liegt jedoch eine besitzlose Verpfändung des fremden Sklaven zugrunde, weswegen der - folgt 
dieses Klagsziel der Konträrklage, wonach der Pfandgeber an der übergebenen, fremden Sache Eigentum erlangen solle, einwenden, dass der Schuldner der besicherten Verbindlichkeit mit dem Erwerb einer neuen Sache zusätzlichen finanziellen Aufwand hat ${ }^{173}$, was in letzter Konsequenz auch das auf Erfüllung seiner Forderung gerichtete Interesse des Gläubigers gefährdet. Dem lässt sich aber zum einen entgegenhalten, dass der Gläubiger selbst dann mit der actio pigneraticia contraria klagen kann, wenn der Schuldner zahlungsfähig und bereit wäre, vorzeitig die Schuld zu begleichen ${ }^{174}$. Zum anderen sind Fallkonstellationen denkbar wie die nachträgliche Einholung der Zustimmung des Eigentümers, was mittels ratihabitio zur Drittpfandbestellung führte ${ }^{175}$ : Dies war von der Musterformel der actio Serviana gedeckt und zur Durchsetzung des Pfandrechtes bedurfte es keiner Modifikation derselben, keiner actio utilis ${ }^{176}$.

Die Fallkonstellation, wonach der Schuldner den Erwerb einer fremden Sache schuldet, um dem Gläubiger daran ein dingliches Recht zu verschaffen, ist grundsätzlich vergleichbar mit jener des Verschaffungslegats: Auch hier wird die Übergabe einer bestimmten Sache geschuldet, die der Verpflichtete (hier: der Erbe) erst erwerben muss. Wenn diese Verschaffung unterbleibt oder scheitert ${ }^{177}$ - etwa weil die Sache zu teuer verkauft würde oder ihr Eigentümer sie nicht verkaufen will ${ }^{178}$ - dann muss der Erbe dem Begünstigten

man Wubbe - nachträglich erfolgte, rechtsgeschäftliche Erwerb der res aliena nicht auf Wunsch oder unter Klagedrohung des Gläubigers hatte erfolgen können. Auch hier ist also kein Beleg für die Konvaleszenz des Pfandrechts zu entnehmen, der eine Klage aus dem contrarium iudicium vorausgegangen ist.

173 Dagegen ließe sich das das zugegebenermaßen auf eine besondere Fallkonstellation abzielenden Argument ins Treffen führen, dass der Erwerb der neuen Pfandsache nicht notwendiger Weise entgeltlich sein müsse.

174 Vgl. D. 13,7,32 (Marc. 4 reg.) und dazu oben unter 3.

175 Vgl. etwa D. 13,7,20pr. (Paul 29 ad ed.): 'Aliena res pignori dari voluntate domini potest: sed et si ignorante eo data sit et ratum habuerit, pignus valebit - Eine fremde Sache kann mit Willen des Eigentümers zu Pfand gegeben werden: Aber wenn sie ohne sein Wissen gegeben wurde und er es gebilligt hat, dann ist das Pfandrecht wirksam. Vgl. auch D. 20,1,16,1 (Marc. lib sing. de form. hyp.); D. 22,3,23 (Marc. lib sing. de form. hyp.).

176 Vgl. Schanbacher, Konvaleszenz (supra, n. 1) S. 12. Zum Problem vgl. Wubbe, Res aliena (supra, n. 26), S. 109; A. Wacke, Ratum habere, Dogmengeschichtliche Grundlagen von Bestätigung und Genehmigung, zss romAbt 121 (2004), S. 344-362, 352-353.

177 Vgl. dazu allgemein Gai. Inst. 2.202, 262; D. 30,39,7 (Ulp. 21 ad Sab.).

178 So in D. 30,71,3 (Ulp. 51 ad ed.): 'Qui confitetur se quidem debere, iustam autem causam adfert, cur utique praestare non possit, audiendus est: ut puta si aliena res legata sit negetque dominus eam vendere vel immensum pretium eius rei petere adfirmet, aut si servum hereditarium neget se debere praestare, forte patrem suum vel matrem vel fratres naturales: aequissimum est enim concedi ei ex hac causa aestimationem officio iudicis praestare' - Wer zwar zugibt, dass er etwas schulde, aber einen gerechtfertigten Grund 
Schadenersatz leisten ${ }^{179}$. Gegenstand der Obligation aber war nur die Herausgabe der vermachten fremden Sache ${ }^{180}$.

In beiden Fällen ist die Leistung - und damit verbunden: die Verschaffung einer konkreten, fremden Sache geschuldet.

Die Analyse der einschlägigen Quellen zum Pfandrealvetrag über eine res alie$n a$ hat ergeben, dass der Pfandbesteller mit der Konträrklage - unabhängig

angibt, warum er nicht leisten kann, muss gehört werden: Wie etwa wenn eine fremde Sache vermacht worden ist und er sagt, dass der Eigentümer sie nicht verkaufen wolle oder wenn er bekräftigt, dass dieser einen unverhältnismäßig hohen Preis für diese Sache verlange, oder wenn er sagt, dass er einen vererbten Sklave nicht leisten könne, vielleicht seinen Vater oder seine Mutter oder leibliche Brüder: Es ist äußerst billig nämlich, ihm dann zuzugestehen, dass er in diesem Fall auf Grundlage der Schätzung vom Richter leisten werde'.

Und in D. 32,14,2 (Gai. 1 fideicomm.): 'Sed si cui legatum relictum est, ut alienam rem redimat vel praestet, si redimere non possit, quod dominus non vendat vel immodico pretio vendat, iustam aestimationem inferat - Aber, wenn jemandem ein Vermächtnis hinterlassen worden ist, dass er eine fremde Sache kaufe oder leiste, dann soll er auf eine gerechtfertigte Schätzung hin erlegen, wenn er die Sache nicht kaufen kann, weil der Eigentümer sie nicht verkauft oder zu unverhältnismäßigem Preis'.

In diesen Fällen muss der Erbe nicht den vom klagenden Legatar geschätzten, sondern den von Richter (objektiv) festgelegten Wert der vermachten Sache zahlen. Anders trifft Iavolen/Labeo scheinbar keinen Unterschied zwischen dem leistungsunfähigen und dem leistungsunwilligen Erben in D. 32,30,6 (Iav. 2 post. epit. Lab.): 'Si aedes alienas ut dares damnatus sis neque eas ulla condicione emere possis, aestimare iudicem oportere Ateius scribit, quanti aedes sint, ut pretio soluto heres liberetur. Idemque iuris est et si potuisses emere, non emeres - Wenn du aber verpflichtet bist, dass du fremdes Haus leisten sollst und du es unter keiner Bedingung kaufen kannst, dann, schreibt Ateius, muss der Richter schätzen, was das Haus wert ist, damit der Erbe nach Zahlung des Preises befreit werde. Das Gleiche ist rechtens, wenn du nicht kaufst, obwohl du hättest kaufen können'.

Der Schlusssatz in D. 30,32,6 ist allerdings der Interpolation verdächtigt worden, vgl. Medicus, Zur Funktion (supra, n. 99), S. 86 Anm. 59. Albers, Perpetuatio (supra, n. 99), S. 203-204 geht auf dieses Problem nicht ein.

179 Albers, Perpetuatio (supra, n. 99), S. 206-210 macht dies von einer confessio des Erben, nicht leisten zu können, abhängig.

180 Vgl. Medicus, Zur Funktion (supra, n. 99), S. 85-86: Die Leistung der aestimatio ist 'keine Alternative, die der Beschwerte frei wählen kann', sondern die 'Befugnis zur Befreiung durch Zahlung wird als Privileg aufgefasst'. Nach Albers, Perpetuatio (supra, n. 99), S. 206, war allein die fremde Sache geschuldet, die Sekundärleistung erklärt Albers aus der confessio in iure, dass die Beschaffung unmöglich sei, und dem deswegen vom Prätor gewährten Privileg einer aestimatio; vgl. ferner M. Müller-Ehlen, Hereditatis petitio, Studien zur Leistung auf fremde Schuld und zur Bereicherungshaftung in der römischen Erbschaftsklage, Köln-Weimar-Wien 1998, S. 176 Anm. 4. 
von seinem dolus - auf das Interesse des Pfandgläubigers verurteilt werden kann: Dieses bemisst sich am Interesse, eine Sache zu erhalten, die als Pfand verwertbar ist. Die res aliena erfüllt diese Voraussetzung nicht. In keinem der Fragmente aus D. 13,7 aber ist die gängig vertretene Ansicht niedergelegt, dass der Pfandgläubiger dann einen Anspruch auf Bestellung der Ersatzsache habe, die im Eigentum des Pfandbestellers steht. Vielleicht geht diese Interpretation, wie von Hausmaninger / Selb ursprünglich behauptet ${ }^{181}$, auf eine Regelung Justinians zurück.

\subsection{Exkurs: Die Basilikenscholien zu D. 19,2,9pr.}

Ein indirektes Indiz dafür, dass im justinianischen Recht die Vorstellung einer erzwingbaren naturalen Befriedigung zumindest auch vertreten worden sein könnte, liefern die Basiliken-Scholien:

Noch einmal ist dazu auf D. 19,2,9pr. zu verweisen ${ }^{182}$ : Wie bereits ausgeführt, kann der Vermieter einer fremden Sache nach deren Eviktion einer Verurteilung ex conducto entgehen, wenn er bereit ist, dem Mieter eine gleichwertige Wohnung zur Verfügung zu stellen. Auch hier besteht weder ein Anspruch auf eine Ersatzleistung, noch kann der Vermieter dazu verurteilt werden: Die Klage des Mieters geht auf Erfüllung (auf das frui licere), die Stellung einer habitatio non minus commoda ermöglicht es dem Vermieter, eine condemnatio pecuniaria unter Umständen abzuwenden. Dann nämlich sei es äußerst billig, wenn der Richter von einer Verurteilung absehe: aequissimum esse ait absolvi locatorem.

Auch die Basiliken berichten für den Fall der Eviktion der Bestandsache in Bas. 20.1.9pr. (= BT 984/6-8) von dieser Möglichkeit:

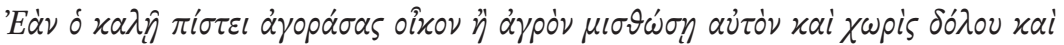

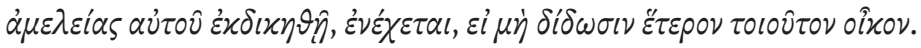

Wenn einer in gutem Glauben ein Haus gekauft hat oder einen Acker, diesen vermietet und ohne Arglist oder Fahrlässigkeit dessen er evinziert wird, so haftet er (aus dem Mietvertrag), wenn er nicht ein anderes solches Haus bereitstellt.

Wie in D. 19,2,9pr. ist im Basilikenfragment die Ersatzleistung eines solchen

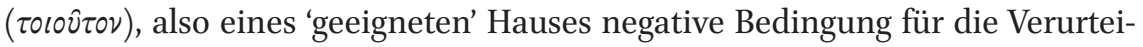
lung, eingeleitet mit: $\varepsilon i \mu \eta \dot{\eta}$ - wenn nicht. Dass dieses Angebot einer Ersatzsache allerdings erst vom Richter als Erfüllung gewertet und gebilligt werden muss,

181 Vgl. Hausmaninger / Selb, Römisches Privatrecht (supra, n. 40), S. 277.

182 Vgl. dazu oben S. 12-15. 
verschweigt der Basilikentext bereits. Er suggeriert damit, dass diese Ersatzleistung jedenfalls absolutorisch wirkt.

In den Basilikenscholien zu dieser Stelle wird der Sachverhalt länger ausgeführt (Bas. Schol. 20.1.9 = BS 1172/17-26):

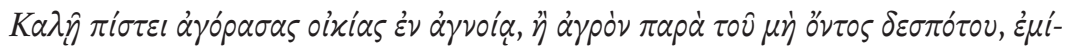

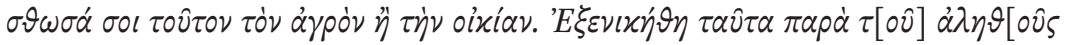

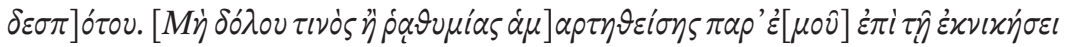

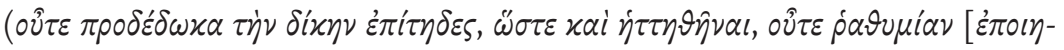

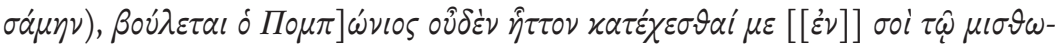

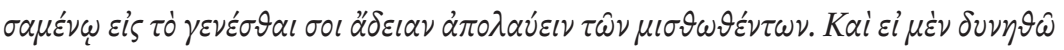

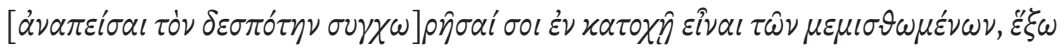

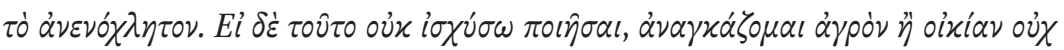

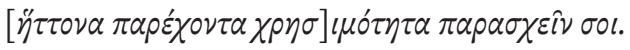

Gutgläubig habe ich ein Haus gekauft, im Unwissen darüber, oder einen Acker, vom Nichteigentümer, und dir diesen Acker oder das Haus vermietet. Dies wurde vom wahren Eigentümer evinziert. Obwohl keine Arglist oder Fahrlässigkeit von mir verübt worden ist (weder habe ich den Prozess absichtlich aufgegeben, sodass er verloren wurde, noch habe ich eine Sorglosigkeit verübt), möchte Pomponius, dass ich um nichts weniger dir, dem Mieter, hafte für den ungestörten Genuss der Bestandsobjekte. Und wenn ich den Eigentümer überreden kann, dir zuzugestehen, das Bestandsobjekt zu besitzen, so werde ich unbehelligt bleiben. Wenn ich dies aber nicht zu bewirken vermag, werde ich gezwungen, einen Acker oder ein Haus dir zur Verfügung zu stellen, das keine geringere Nutzbarkeit aufweist.

Ego vermietet Tu ein Haus oder eine Liegenschaft, von der er nicht weiß, dass sie fremd ist. Es kommt zur Eviktion. Obwohl den Ego daran kein Verschulden treffe, verlangt Pomponius nichtsdestotrotz, dass der Ego dem Tu auf den Genuss des Bestandsobjektes hafte. Dies könnte etwa dann gewährleistet werden, wenn Ego den Eigentümer dazu überredet, dem Mieter Tu die von Ego eingeräumten Nutzungsrechte zuzugestehen - dann bliebe Ego unbehelligt. Der nun folgende Satz hinsichtlich der Konsequenz für Ego, die ihm droht, wenn er den Eigentümer nicht überreden kann, ist von vordringlichem Interesse: Wenn Ego dies vom Eigentümer nicht bewirken kann, dann wird er gezwun-

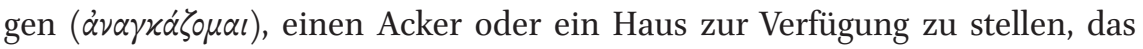
nicht weniger Annehmlichkeiten bietet als das Bestandsobjekt. Das Verb à $\alpha \gamma \varkappa \alpha ́ \zeta \varepsilon \sigma \vartheta a \iota$ ('zwingen') nun lässt sich nicht mehr mit einer freiwilligen 
Ersatzleistung in Einklang bringen, sondern wird als Pflicht des Vermieters zu verstehen sein. Auch Kyrillos interpretiert die Leistung einer Ersatzwohnung

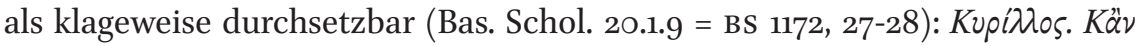

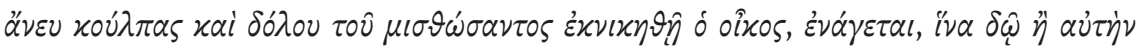

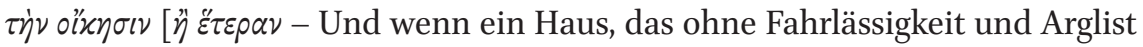
vermietet wurde, evinziert worden ist, so wird darauf geklagt, dass man (= der Vermieter) dieses Haus gibt oder ein anderes.

Beide Leistungen sind in dieser Darstellung also Gegenstand der Klage, des

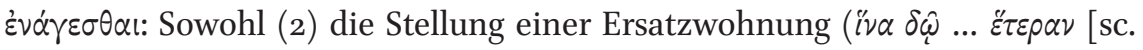
olk $x \sigma l v]$ ) als auch (1) die Ermöglichung der Nutzung im vermieteten Objekt (iva $\left.\delta \hat{\omega} \ldots \alpha \dot{v} \tau \dot{\eta} \nu \tau \dot{\eta} \nu o^{\prime \prime} x \eta \sigma \nu\right)$.

Die hier zitierten Basilikenscholien bilden als Scholia vetera das Rechtsverständnis aus der Zeit der Kompilation $\mathrm{ab}^{183}$, sind also älter als die Basiliken, natürlich aber jünger als die bei Ulpian referierte Entscheidung des Pomponius. Der hochklassische Jurist appelliert dort an den Richter, von einer Verurteilung abzusehen, wenn der Schuldner zur naturalen Befriedigung durch adäquaten Ersatz bereit ist. In den Basilikenscholien erscheint diese Möglichkeit hingegen bereits als gerichtlich durchsetzbarer Anspruch: Diese Entscheidung könnte vom justinianischen Recht beeinflusst sein, welches die Sachkondemnation zumindest kannte ${ }^{184}$. Für D. 13,7,9pr. ist aber auch diese Interpretation durch die Basiliken nicht beleg ${ }^{185}$, eine Deutung, welche weder für D. 19,2,9pr.186 noch für D. 13,7,9pr. dem klassischen römischen Recht entspricht.

183 Vgl. dazu nur H. de Jong, Using the Basilica, zss romAbt 133 (2016), S. 286-321, 291 u. 295296.

184 Diese Frage kann hier nicht vertieft werden, vgl. dazu etwa L. Wenger, Zu drei Fragen aus dem römischen Zivilprozeßrechte (Eine Nachlese), zss romAbt 59 (1939), S. 315-389, 326327, M. Kaser, Das römische Privatrecht, Zweiter Abschnitt, München ${ }^{2} 1975$, S. 344 und Kaser / Hackl, Das Römische Zivilprozessrecht (supra, n. 53), S. 6o9-611, die einen Grundsatz der Sachkondemnation auch im justinianischen Recht annehmen wollen; Zimmermann, The Law of Obligations (supra, n. 52), S. 773, der die Sachkondemnation für dare und reddere-Obligationen bejaht; Winkel, Specific performance (supra, n. 53), S. 13-16, welcher auch für das justinianische Recht grundsätzlich die Möglichkeit der Geldkondemnation favorisiert; vgl. ferner zum Forschungsstand H. Dilcher, Geldkondemnation und Sachkondemnation in der mittelalterlichen Rechtstheorie, zss romAbt 78 (1961), S. 277-307, 278-283; Nehlsen-von Stryk, Grenzen des Rechtszwangs (supra, n. 52), S. 538-540.

185 Bas. Schol. 25.1.9 = BS 1772/30 - 1774/12 enthalten keine Auseinandersetzung mit B. 25.1.9pr.

186 Vgl. dazu auch G. Schiemann, Rez. U. Wolter, Das Prinzip der Naturalrestitution in $\S 249$ $B G B$, Herkunft, historische Entwicklung und Bedeutung, Berlin 1985, in: zss romAbt 117 (1990), S. 663-666, 665 gegen Windscheid, Lehrbuch (supra, n, 37) § 257 Anm. 6, der diese Passage als Ausgangspunkt für die Abkehr von der condemnatio pecuniaria angesehen 
Es gilt zu differenzieren zwischen der condemnatio des Beklagten, die im Formularprozess stets auf Geld gelautet hat, und der Frage, worin seine Leistungspflicht bestanden haben könnte: Selbst die Interpretation von D. 19,2,9pr. in den Basiliken lässt nicht erkennen, dass der Vermieter auf 'Bestellung einer Ersatzwohnung geklagt werden kann'. Vielmehr wird er in der Darstellung von Bas. Schol. 20.1.9 dazu gezwungen, also verurteilt. Geschuldet war hingegen eine Ermöglichung, das Bestandsobjekt so wie vereinbart zur Nutzung zur Ver-

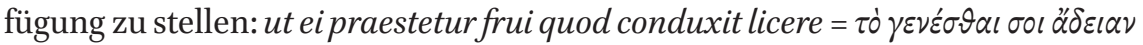
$\dot{\alpha} \pi \circ \lambda \alpha \dot{\varepsilon} \varepsilon \imath \nu \tau \hat{\omega} \nu \mu \iota \sigma \vartheta \omega \vartheta \dot{v} \tau \tau \omega \nu$.

\section{2. $\quad$ Fazit}

Auch der Gläubiger, welcher eine res aliena pfandweise übergeben erhält, kann nicht bewirken, dass der Schuldner zur Stellung eines Ersatzpfandes verurteilt wird. Und dies schuldet der debitor aus D. 13,7,9pr. ja auch nicht. Nach Auslegung der demonstratio der actio pigneraticia in personam contraria liegt vielmehr näher, dass sich die Pflicht des Pfandbestellers auf die res pignori data selbst bezieht, auf jene Sache also, die hingegeben wurde, auf jene Sache qua de agitur, denn sie ist ja auch Gegenstand der conventio und damit Gegenstand des Pfandrealvertrags, der mit ihrer Übergabe begründet worden ist. Wenn also - und auch das ist Hypothese - tatsächlich ein Verhalten des Pfandbestellers geschuldet war, so könnte dies maximal der Erwerb der fremden, hingegebenen Sache sein, um dem Pfandgläubiger so zumindest den Rechtsschutz der actio Serviana utilis zu ermöglichen. Auch diese Überlegung lässt sich aus dem Text heraus nicht belegen, und stellt im Grunde ja nur eine Variation der breit vertretenen und hier bekämpften Lösung dar, wonach der Pfandgeber die Bestellung eines Ersatzpfandes schuldet; eine Variation freilich, die der Konzeption des Realvertrags und seiner Klage vielleicht näherkommt, da man diese Auslegung seiner vertraglichen Pflicht einzig auf die tatsächlich übergebene Sache bezieht und nicht auf eine andere, neue Sache.

Ungeachtet dieser Überlegungen konnte post litem contestatam zweifelsohne eine absolutio eintreten, wenn der Pfandgeber freiwillig ein Ersatzpfand bestellte. Die condemnatio pecuniaria erscheint auch hier als 'extrema ratio' für den 'nicht restitutionswilligen Beklagten'187, für den Pfandgeber also, der nicht die Bestellung eines adäquaten Ersatzpfands angeboten hatte. Nach dem Stand der Quellen war dies aber weder im Prozess erzwingbar noch überhaupt geschuldet.

habe. U. Wolter, Das Prinzip der Naturalrestitution, Herkunft, historische Entwicklung und Bedeutung, Berlin 1985, S. 77 geht darauf nicht weiter ein.

187 So allgemein Buzzacchi, Omnia iudicia (supra, n. 66), S. 15; ähnlich auch Cannata, Omnia iudicia (supra, n. 52), S. 68-69. 